\begin{abstract}
There is theoretical evidence that economic and family policies have an important impact on mother's employment. The aim of this article is to study empirically the women's transitions from employment to non-employment after they have their first birth in Belgium, WestGermany, Italy, Spain and Sweden. The paper investigates the evolution of post-birth employment across time and how these shifts are related to - cross-country - different policies and society. We also test if the withdrawal from work is due to marriage or to motherhood. Results show that Spain and West-Germany are the countries with the lowest rates of stayingon in the labour market after childbearing. Higher education is a key explanatory factor of the probability of post-birth employment in all countries, except for Sweden. In the period 1973-93, Belgian and especially Spanish mothers increased their probability of post-birth employment, ceteris paribus. The opposite movement occurred in West-Germany. Italy and Sweden remained fairly constant. This trend is mainly explained by the taxation system (joint $v s$. separate), education and part-time employment.
\end{abstract}

JEL Classification: I20, J13, J18, J20

Key Words: employment transitions, part-time work, motherhood, education.

This paper was produced as part of the Centre's Labour Markets Programme

\title{
Acknowledgements
}

I would like to thank Professor Stephen Nickell for his helpful comments and suggestions. I would also like to thank participants at the CEP Labour Workshop and IZA Family and Work Conference. Financial help from the "Fundaci'on Ram'on Areces" is acknowledged, as well as the United Nations for the provision of data. I am responsible for any remaining errors.

Maria Gutiérrez-Domènech is a member of the Centre for Economic Performance, London School of Economics. Correspondence to: CEP, LSE, 10 Portugal Street, London WC2 2AE. E-mail: Maria.Gutierrez-Domenech@1se.ac.uk

Published by

Centre for Economic Performance

London School of Economics and Political Science

Houghton Street

London WC2A 2AE

(C) Maria Gutiérrez-Domènech, submitted March 2003

ISBN 0753016044

Individual copy price: $£ 5$ 


\section{Employment After Motherhood: A European Comparison}

\section{Maria Gutiérrez-Domènech}

May 2003

1. Introduction and Literature 2

2. Data and Covariates 4

2.1 Countries 5

$\begin{array}{lll}2.2 & \text { Variables } & 6\end{array}$

3. Country Comparison: Labour Market, Taxation and Welfare Policies 7

4. Descriptive Statistics 9

$\begin{array}{ll}\text { 4.1 The Withdrawal of Women from Work } & 10\end{array}$

4.2 Is the Withdrawal from Work Due to Marriage or to Motherhood? 14

5. Model 16

6. Simulation 20

$\begin{array}{ll}\text { 7. Policy Evaluation } & 25\end{array}$

$\begin{array}{lll}\text { 8. Conclusions } & 27\end{array}$

References $\quad 29$

Appendices $\quad 31$

The Centre for Economic Performance is financed by the Economic and Social Research Council. 


\section{Introduction and Literature Review}

There is theoretical evidence that labour and family policies have an impact on female labour supply, especially amongst mothers. In his book, Becker (1993) models female labour supply taking into account family decisions. Women with children allocate their time between the labour market and childcare. There are several factors that determine their choice: preferences and cultural aspects, the price of childcare, possible substitutes for childcare and family taxation policies. All these elements play a fundamental role in a mother's employment decision and consequently, in the transitions from employment to non-employment after first birth. In order to evaluate how various policies affect female participation around childbearing, cross-country and cross-time comparison is important.

Transitions to non-employment after childbearing matter because they are likely to cause a loss in human capital and future wages, and this effect is expected to be larger the longer the time spent out of work. For example, Beblo and Wolf (2002) find evidence that discontinuous employment caused by maternal leave reduces the wage for females, ceteris paribus. Depending on the economic situation and governmental rules, women might face barriers to return to work after a period of childcare leave.

In this paper we investigate the transitions of women from employment to non-employment after first birth. We analyse the factors that increase or reduce employment after childbearing and, for fixed characteristics, how this depends on specific country behaviour. We also explore how the expected probability of employment after birth has evolved over time. We focus on Belgium, West-Germany, Italy, Spain and Sweden since these exhibit substantial differences in policies and social behaviour.

Although this issue has been addressed in these countries (especially in Germany and Sweden), our contribution is to make a comprehensive comparison and harmonise research on the likelihood of employment after first birth. We use the same data (Family and Fertility Survey) for each country and select identical variables, cohorts and time horizon. We trace the post-birth employment probability for a representative recent mother. That is, we determine the chances of employment after childbearing of a woman with certain characteristics, given that she is in any of the countries under examination. Differences in predictions for employment across countries are caused by distinct policies and/or unobserved heterogeneity that we do not capture with our controls. Our aim is also to identify the effect of changes in policies on employment after birth.

These countries differ in the rigidity of their labour markets (particularly the non-availability of part-time jobs), family taxation and subsidised childcare. ${ }^{1}$ These factors have been shown to affect simultaneously fertility and female labour supply. For example, Del Boca (2002) uses panel data from the Bank of Italy to analyse how imperfections in the labour market and characteristics of the publicly-funded childcare system discourage both family

\footnotetext{
${ }^{1}$ They have also differences in cultural-family rules. In Southern Europe, grandparents are more likely to live in the same household, providing indirect childcare. However, their effect on childcare could go either way if they require health assistance.
} 
formation and participation in Italy. Apps and Rees (2001) find evidence that countries with individual rather than joint taxation are likely to have at once high fertility and female labour supply. They also show that family support through improved availability of options for domestic childcare is more effective for female participation than direct child payments.

The withdrawal of women from work has been studied for several single countries. Dex, Joshi, McCulloch and Macran (1996) use the 1958 National Child Development Study cohort to model employment transitions around childbearing in the UK. They find that education is the main factor that secures women's job continuity after motherhood. Contrary to what the authors expected, delaying motherhood helps high-educated women to remain at work but it is not essential. For the US, Desai and Waite (1991) test if the occupational sex composition ${ }^{2}$ determines the likelihood that recent mothers are employed. They find that the probability of being employed after childbearing depends mainly on those occupational characteristics that raise the opportunity cost of being in the labour force, independently of sex composition. They also distinguish between women with high and low work commitment depending on their answer to the question if they plan to work at age 35. As expected, they find that those who said yes had a greater probability of remaining at work after motherhood. However, women with low commitment were more responsive to financial pressures and worked when they had to. Ondrich, Spiess and Yang (1996) study the return to work after childbirth in Germany using a hazard approach. They focus on the legal parental leave period and the post-parental leave. Their results show that once the protection expires, mothers with strong labour force attachment (measured by years of experience and pre-birth full-time contracts) are more likely to return.

Motherhood employment has been extensively studied in Sweden. For instance, Rönsen and Sunström (1996) look at mother's employment transitions around birth in Sweden and Norway. They use a hazard approach to analyse the entry into employment after birth, with special focus on the effect of parental leave policies. They find that women who have the right to a paid leave are much more likely to resume employment in both countries. Bernhardt (1986) analyses women's home attachment at first birth, using a logistic model for three educational groups. She concludes that the likelihood of being at home 12 months after confinement is significantly affected by education, marital status, early labour-force withdrawal and duration of the union. Furthermore, the paper shows that low educated women have become over time closer to other educational groups in terms of home attachment. Bernhardt (1988) writes about the increasing tendency to reduce working hours among one-child mothers, particularly among women with a low level of education. Part-time work has become the 'combination strategy' (family and work) for both women who previously would have selected the 'home strategy' and for those who would have taken the 'career strategy', as the author defines it. Similar results are developed in Ellingsaeter and Ronsen (1996) and Kravdal (1992) for Norway. In the 80s, Norwegian labour force participation rates for mothers with the youngest child under 3 years increased substantially from $47 \%$ to $69 \%$. This increase was accompanied by a rise in part-time work, partly thanks to the state, which is a good creator of part-time jobs.

\footnotetext{
${ }^{2}$ They call female occupations those with a majority of women in the market.
} 
In Southern Europe, Adam (1996a) uses the Spanish Household and Expenditure Survey (ECPF) for the period 1985-90 to study married women's labour force transitions. The advantage of the Family and Fertility Spanish data is that it has richer information about women $^{3}$ but its greatest weakness compared to hers is that there are no income covariates. The author concludes that children are the main reason for mothers' abandoning the labour force. However, the principal cause of re-entry is the insecurity of husband's employment rather than children.

Although the vast majority of research has been done for single countries, there are, however, two papers that deal with more than one country. Gustafsson, Wetzels and Vlasblom (1996) compare women's labour force transitions related to childbirth in Germany, Sweden and Great Britain. They use different panels for each country: the GSOEP for Germany, the Swedish HUS and the British BHPS. Their results show that German and British women have higher full-time employment pre-first-birth. German women stay longer at home with children because of their breadwinner regime. They find evidence that the accumulation of human capital is a main determinant for re-entry in Germany and Great Britain whereas it is not in Sweden. Another study by Saurel-Cubizolles, Romito, Escribà-Agüir, Lelong, Pons and Ancel (1999) describes the return to work after childbirth in France, Italy and Spain, and how this is related to their different maternity leave policies. They also use different surveys ${ }^{4}$ for each country to undertake their analysis. Their results show that the percentage of women coming back to work within a year after the birth is around $80 \%$ in both France and Italy. The proportion is lower in Spain $(53 \%)$. The gap of post-birth leave was related to each country's policies. For example, Italian women returned to work later, which they say is due to their longer post-birth maternity leave.

The paper is organised as follows: in Section 2, we explain our data sources. In Section 3 we describe the labour market, maternity leave and taxation regimes in Belgium, WestGermany, Italy, Spain and Sweden. We look at the transitions across these countries in Section 4 with a description of the staying-on-rates in employment after childbearing. We next focus on our model in Section 5. The aim is to analyse the probability of employment after motherhood, given females' observed characteristics and labour market conditions. In Section 6 we simulate the foreseen post-birth employment of a representative individual if she was employed before the birth and living in each of our studied countries. We proceed with an evaluation of the impact of policies on post-birth employment in Section 7. We then conclude in Section 8.

\section{Data and Covariates}

The data come from the Family and Fertility Survey (FFS). The structure of the questionnaire was originally produced by the United Nations but the collection was undertaken by

\footnotetext{
${ }^{3}$ Adam (1996b) points out in her paper the shortcoming of ECPF, which is the lack of female's education, experience and regions.

${ }^{4}$ Their sample for Spain only covers the Valencian region.
} 
different institutions. ${ }^{5}$ This has caused variations in the available explanatory variables since not all the proposed questionnaire sections were applied in all countries. Despite this drawback, these data have the advantage that whenever we have coinciding variables, they derive from the same question and have the same interpretation. For our analysis, we have selected those relevant explanatory variables that exist in all five countries in order to estimate the probability of post-birth employment.

Each individual responds to the survey at a particular moment of time. Then, she is asked to give information about her past. That is, the poll asks every woman to build up her history. For instance, the dates of her marriage, first cohabitation, sequence of jobs (starting and ending date of her job for up to 30 different employments), calendar of children born and sequence of schooling (up to 10 different courses). In consequence, since it is a retrospective survey, there will be errors coming from the individuals' lack of memory. Another shortcoming of this survey is the lack of wage and income variables. For our estimation analysis we select those women who had at least a first birth.

\subsection{Countries}

\subsubsection{Belgium: Flemish and Brussels capital region ${ }^{6}$}

Belgian data were collected in the Flemish and Brussels capital region between 1991 and 1992. Therefore, our results are not representative of the whole of Belgium, but only for the Flemish and Brussels capital region. The number of valid interviews was 2088 for women and 1319 for men, obtained with a percentage of responses of $69.2 \%$ and $66.3 \%$ respectively. Individuals were between 20 and 41 years old.

\subsubsection{West-Germany}

The survey file contains information on 5036 persons (2024 men and 3012 women) born between 1952 and 1972, aged 20-39 on $1^{\text {st }}$ January 1992. Interviewing took place in 1992.

\subsubsection{Italy}

The target population was women and men aged 20-49. The interviews were carried out between November 1995 and January 1996. There were 4824 women interviewed and 1206 men.

\subsubsection{Spain}

The data come from the Spanish Family and Fertility Survey, a data set collected by the Centro de Investigaciones Sociólogicas (CIS) between June and November of 1995. The sample is built at the national level with individuals aged between 18 and 49 years old. The number of valid interviews was 4021 for women and 1991 for men, obtained with a percentage of responses of $83.6 \%$ and $77 \%$ respectively.

\footnotetext{
${ }^{5}$ We obtained FFS directly from the United Nations. We have FFS project number 93, approved by the FFS commission.

${ }^{6}$ From now on, any time we talk about Belgium we only refer to the Flemish and Brussels capital regions.
} 


\subsubsection{Sweden}

The Swedish Family Survey conducted in 1992/93 consists of eight cohorts: women born in 1949, 1954, 1959, 1964 and 1969; men born in 1949, 1959 and 1964. The interviews took place at the end of 1992 and at the beginning of 1993. A total of 4229 women and 2177 men were included in the sample, altogether 3318 women and 1666 men were interviewed.

\subsection{Variables}

A major effort has been undertaken to select those explanatory variables ${ }^{7}$ that are comparable across our countries. These are the following: size of the city of origin (City), being religious (Religious), education, cohort, married at first birth (Married1C), monthly working experience from 15 years old to the pre-birth job (Experience), age at first birth and its square (AgeAt1C and AgeAt1C2), age of first job (AgeAt1Job). All explanatory variables are taken at one year pre-birth, except for education. ${ }^{8}$ The scale of the degrees in education goes from zero to six in accord with the International Standard Classification of Education (ISCED). From this variable, we have constructed four dummy variables E1 (with value one if the maximum level is 0 or 1 , primary school), E2 (one if the individual belongs to category 2 or 3, secondary school), E3Voc (one if she has level 4, vocational degree) and E3GrPo (one if she is at 5 or 6 , graduate or post-graduate degree). Our reference category is the lowest level E1. Notice that category E3Voc does not exist either in Italy nor in Sweden. We also control for post-confinement duration dummies and calendar year dummies.

In order to make our sample consistent across countries, we select cohorts born between 1951 and 1970 and observable calendar years up to 1993. Surveys in Spain and Italy were undertaken in 1995, which means that individuals of the same cohort might be observed longer compared to the other countries. ${ }^{9}$ We restrict those individuals to be followed-up until 1993. In Sweden, we have women for five specific cohorts: 1949, 1954, 1959, 1964 and 1969. This means that we have not been able to completely homogenise cohorts. Nevertheless, we believe that our results are fairly comparable. For the estimation, we select those women who had a first birth. We have 1969 observations in Belgium, 1350 in West-Germany, 2856 in Italy, 2470 in Spain and 2291 in Sweden. 
Table 1: Maternity Leave and Benefits ${ }^{1}$ : 1975-97

\begin{tabular}{l|cccc|cccc}
\hline \hline & \multicolumn{4}{|c}{ Duration of leave } & \multicolumn{4}{c}{ Cash benefits $^{3}$} \\
\hline \hline Countries & 1975 & 1985 & 1990 & 1997 & 1975 & 1985 & 1990 & 1997 \\
\hline Belgium & 14 & 14 & 14 & 15 & 60 & 80 & 80 & 77 \\
Germany & 14 & 14 & 14 & 14 & 100 & 100 & 100 & 100 \\
Italy & 22 & 22 & 22 & 22 & 80 & 80 & 80 & 80 \\
Spain & 12 & 14 & 16 & 16 & 75 & 75 & 75 & 100 \\
Sweden & 30 & 51 & 51 & 64 & 90 & 70 & 71 & 62 \\
\hline \hline
\end{tabular}

${ }^{1}$ Source: Gauthier (2000) and Moss and Deven (1990).

${ }^{2}$ Duration of the leave in weeks.

${ }^{3}$ Cash benefits as a percentage of regular wages.

Table 2: Childcare Leave ${ }^{2}$ Schemes in 1999

\begin{tabular}{l|ccl}
\hline \hline Countries & Duration $^{2}$ & Cash Benefits $^{3}$ & Flexibility \\
\hline \hline Belgium & 3 & $37 \%$ & Up to the child's fourth birthday \\
Germany & $36^{*}$ & $24 \%$ & Immediately after paid maternity leave \\
Italy & 6 & $30 \%$ & Up to the child's ninth birthday \\
Spain & $36^{*}$ & Unpaid & Immediately after paid maternity leave \\
Sweden & 15 & $66 \%$ & Up to the child's eighth birthday \\
\hline \hline
\end{tabular}

${ }^{1}$ Source: Gauthier (2000).

${ }^{2}$ Duration in months.

${ }^{3}$ Cash benefits as $\%$ of wage.

${ }^{*}$ Duration includes the post-birth period covered by the maternity leave.

\section{Country Comparison: Labour Market, Taxation and Welfare Policies}

We summarise in Table 1 the main characteristics of maternity/parental leave ${ }^{10}$ and benefits in these countries. We also provide information on childcare leave ${ }^{11}$ in Table 2.

\footnotetext{
${ }^{7}$ Full description of the variables in Table 13.

${ }^{8}$ Education level is taken at the date an individual completes school, which could occur after the birth. We were obliged to take this measure since schooling calendar is missing in Belgium, West-Germany and Italy. In the latter countries, only the highest level of education at completion date is reported. Despite this, we believe that this variable is adequate at capturing an individual's human capital at birth. First, most women are likely to exit schooling before childbearing. Second, for those who finish later, the final level achieved is a measure of their expectations in the labour market.

${ }^{9}$ Notice that we have a retrospective survey.

${ }^{10}$ The term maternity/parental leave refers to paid leave during the period immediately prior and after childbirth.

${ }^{11}$ Childcare leave refers to optional extended leave after maternity/parental leave.
} 
Table 3: Children in Public Funded Childcare ${ }^{1}$ in 1993

\begin{tabular}{l|cc}
\hline \hline \multicolumn{1}{c|}{ Countries } & Under age of 3 & Age 3 to school age \\
\hline \hline Belgium & $30 \%$ & $95 \%$ \\
Germany $^{2}$ & $5 \%$ & $65 \%$ \\
Italy & $6 \%$ & $97 \%$ \\
Spain & $5 \%$ & $84 \%$ \\
Sweden & $33 \%$ & $79 \%$ \\
\hline \hline
\end{tabular}

\footnotetext{
${ }^{1}$ Source: Gauthier (2000), Moss and Deven (1990) and Tietze and Cryer (1999).

${ }^{2}$ Data from 1988.
}

These data are a subset of those used by Gauthier (2000). Besides maternity and childcare leave, countries differ substantially concerning daycare provision. For example, Moss and Deven (1990) report that 31\% of one-year-old children with working mothers were in the collective daycare system in France, whereas less than $10 \%$ are in Italy or Spain. Table 3 shows that indeed Spain, Italy and Germany are the countries with less public funded childcare. ${ }^{12}$ But not only the quantity and cost of childcare matters but also if it fits working mothers conditions. A paper by Hank and Kreyenfeld (2000) finds that the availability of childcare does not increase female participation in West-Germany. They argue that, despite high rates of available childcare in West-Germany, the opening hours are too limited to satisfy the needs of an employed woman. In Gauthier (2000), the author summarises public policies affecting fertility and families in the $15 \mathrm{EU}$ members. She finds that across all family types, cash support for family tends to be low in Portugal, Spain and the UK. Furthermore, she points out that these cash trends over time are relatively stable, except for some increase in Belgium, Denmark, Germany and Luxembourg. Finally, flexible arrangements provided by firms is another way to facilitate the combination of work and family. Table 4 summarizes data on flexible working arrangements in enterprises as it appears in OECD (2001). Italy and Spain have the lowest percentage of employees reporting that they work flexi-time.

There is also an impact of different taxation systems on the incentives in couple families. The basic issue is whether the income is calculated on the basis of the sum of the two earned incomes (Joint) or on the basis of the two earned incomes separately (Separate). Whatever form of joint tax system is used, there is a priori a reduced incentive for the partner of lower earnings to work (or potential lower earnings) to increase his/her labour supply. In Table 5 we report the type of taxation regime in each country. Except for WestGermany, all countries moved from a Joint to Separate system between 1970 and 1990. Joint taxation has been linked to a breadwinner model (see Sainsbury, 1994) for further details), which is characterised by the strict division of labour. That is, the husband is perceived as the earner and the wife as the carer. Apart from the type of taxation system, there are other family-based tax reliefs and benefits that are relevant for the re-entry in

\footnotetext{
${ }^{12}$ Although this might be partly endogenously driven, we believe that it provides evidence for differences in public funded childcare.
} 
Table 4: Indicators of Family-friendly and Relevant Flexible Working Arrangements in Enterprises $^{1}$, 1995-96

\begin{tabular}{l|ccc}
\hline \hline Countries & $\begin{array}{c}\text { Employer provision } \\
\text { for child day-care }\end{array}$ & $\begin{array}{c}\text { \% of employees reporting } \\
\text { they work flexi-time }\end{array}$ & $\begin{array}{c}\text { \% of women part-time } \\
\text { on a voluntary basis }\end{array}$ \\
\hline \hline Belgium & $14 \%$ & $26 \%$ & $21 \%$ \\
Germany & $16 \%$ & $33 \%$ & $27 \%$ \\
Italy & $5 \%$ & $19 \%$ & $11 \%$ \\
Spain & $8 \%$ & $20 \%$ & $8 \%$ \\
Sweden & $1 \%$ & $32 \%$ & $20 \%$ \\
\hline \hline
\end{tabular}

${ }^{1}$ Source: OECD (2001).

Table 5: Evolution of the Taxation Type ${ }^{1}$

\begin{tabular}{l|ccc}
\hline \hline \multicolumn{1}{c|}{ Countries } & 1970 & 1980 & 1990 \\
\hline \hline Belgium & & \\
Germany & Joint & Joint & Separate \\
Italy $^{3}$ & Joint & Joint & Joint \\
Spain $^{4}$ & Joint & Separate & Separate \\
Sweden $^{5}$ & Joint & Seint & Separate \\
\hline \hline
\end{tabular}

\footnotetext{
${ }^{1}$ Source: OECD (1993).

${ }^{2}$ Belgium moved to Separate system in 1990.

${ }^{3}$ Italy moved to Separate system in 1977.

${ }^{4}$ Spain moved to Separate system in 1989.

${ }^{5}$ Sweden moved to Separate system in 1971.
}

employment after motherhood. Table 14 in Appendix B summarise some standard tax reliefs in 1990.

\section{Descriptive Statistics}

In Gutiérrez-Domènech (2002), we found that Spanish women's employment rates diminish substantially around childbearing and that they do not recover. We now investigate the pattern in these countries with different policy regimes. In our basic analysis, we look at employment patterns after the first birth without controlling for future fertility. In other words, the observed patterns may arise, at least in part, because of different future fertility patterns. Furthermore, the impact of exogenous variables on these patterns of employment may operate either directly or via future fertility. 
Figure 1: Employment Rates Before and After $1^{\text {st }}$ Birth: Country comparison

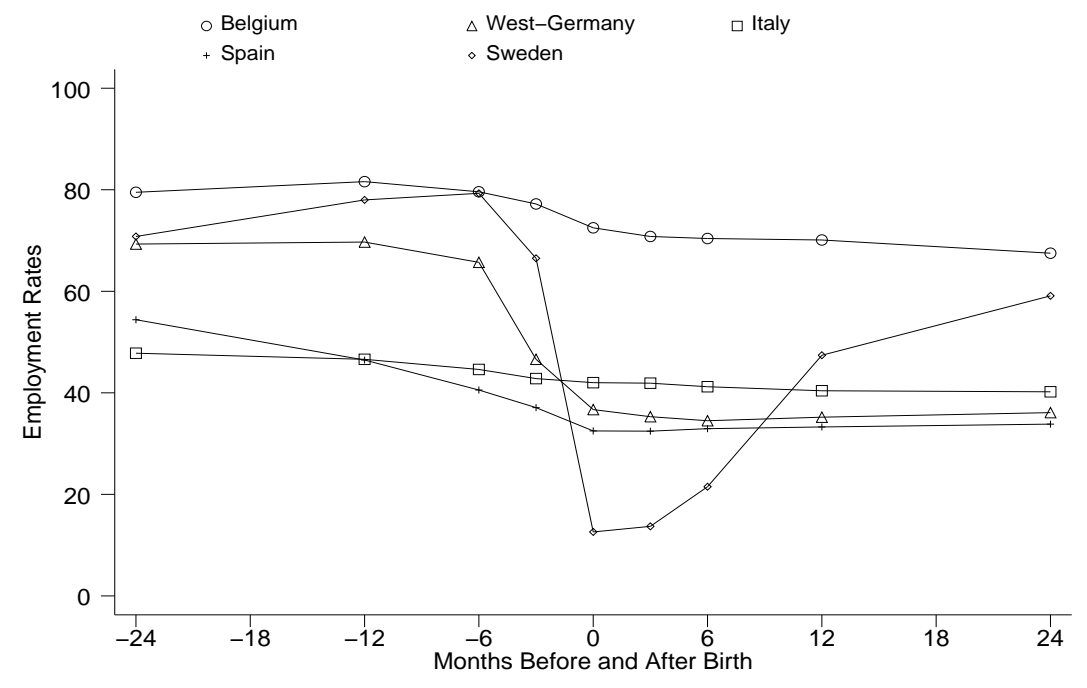

\subsection{The Withdrawal of Women from Work}

In Figure $1^{13}$ we present female employment $\operatorname{rates}^{14}$ around motherhood from Belgium, West-Germany, Italy, Spain and Sweden. We can notice immediately how dissimilar they are, not only in their starting point (24 months before the birth) but also in their evolution. Future first-child mothers' employment rates in Belgium ${ }^{15}$ are about $80 \%$ two years before confinement and experience a slight decline around birth. Belgian employment rates stay at about $67.5 \%$ two years after motherhood. In ten years time, when the procreation process is likely to be over, they still have an employment rate of $65.2 \%$. Thus, the exit rate from the labour market appears to be small. Swedish women experience a huge drop around birth. This is due to the fact that Swedish women are probably responding as non-employed when they are on maternity leave. The same may partly happen in West-Germany. This is not the case in the other countries, where women on leave are accounted as employed. The picture shows the impact of parental leave on labour force and how Swedish mothers recover their pre-birth levels. Actually, data show that ten years after the first child is born, 73.6\% women in Sweden are at work. Thus, once the procreation process is finished, most of them are back in the labour market. German employment rates around childbearing fall considerably from $69.7 \%$ to $36.1 \%$. Interestingly, Spanish and German mothers are the groups who experience the greatest

\footnotetext{
${ }^{13}$ We summarise labour market characteristics for women with and without children in 1998 in Table 15 in Appendix B. We also tabulate activity rates by marital status in 1991 and 1995 (Table 16). The purpose is to see if our results are in line with national statistics. However, note that this data do not coincide with our time horizon (approximately 1965-95).

${ }^{14}$ Employment rates are computed taking into account censoring. For example, there are some women not observed two years after the birth. Thus, they have been subtracted from the total number of mothers in order to compute the rates.

${ }^{15}$ Belgian data was only collected in the Flemish and Brussels regions. Thus, it does not take into account the Walloon area. We would expect employment rates to be lower if this region was also included in the survey.
} 
drop in post-birth employment rates. After 10 years, ${ }^{16}$ their rates are $34 \%$ and $40 \%$ respectively. We have to point out that German mothers are entitled to long and partly paid childcare leave, which is optional after full paid maternity leave. This could explain their low employment rates after motherhood.

We would like to know if the Spanish pattern is typical of other South-European countries too, with more similarities in their labour markets and social life. Figure 1 confirms that indeed Spain is closer to Italy than to Belgium or Sweden. Italian mothers' employment rates decrease from around $51 \%$ to $40 \%$ and they remain at $42 \%$ after ten years. However, the decline in Spain is more significant since it starts at higher employment rates and ends at lower levels.

Figure 7 in Appendix $\mathrm{C}$ represents employment rates around birth by country and cohort. ${ }^{17}$ The largest cohort difference appears to be in Spain, which rate of exit from employment around childbearing has significantly diminished. Curiously, in West-Germany and Belgium, the profile of the two cohorts is very similar with actually slightly higher employment rates for older generations. This is probably due to the increase of unemployment in the $80 \mathrm{~s}$, when cohorts $1958-64^{18}$ where at the age of motherhood. Note that this increase in unemployment happens in Italy and Spain as well. However, their young cohorts experience greater employment rates after childbearing compared to their older counterparts. This suggests that the change in social patterns towards higher participation offsets the negative impact of unemployment in both Spain and Italy.

We next compare transitions in the labour market after motherhood. We take women's labour force status 12 months before the birth and 24 months after since we want to ensure that we do not capture job protection policies in between. Those individuals not observed in the two periods are censored. We define four types of people: $e-e$ means employed at both times, e-ne defines those employed before but not after confinement, ne-e for movements from non-employment to employment and ne-ne for those non-employed either before nor after the birth. Note that non-employment includes both home work and unemployment. This is important for interpreting the meaning of the transitions. That is, in countries and cohorts with high female unemployment rates, part of the transitions to non-employment are related not only to home oriented women but also to unemployed mothers. For example, we would expect that shifts $e$-ne are due to more unemployment in later cohorts in Spain.19

Table 6 shows that indeed Spanish women have the greatest unemployment rates from the 80 s and therefore, they are a priori more likely to have transitions to non-employment linked to unemployment rather than home activities, compared to the other countries. In Table 7 we observe transitions in and out the labour market around childbearing. In

\footnotetext{
${ }^{16}$ Note that in this period of time, further births are possible.

${ }^{17}$ We do not plot Sweden since in this country the sample is constructed with cohorts 49, 54, 59, 64 and 69, and not with all cohorts from 1950 to 1970, as in the other countries.

${ }^{18}$ 'Young Cohort' for the comparison in Belgium and West-Germany.

${ }^{19}$ The proportion of women employed, unemployed and inactive has changed substantially since 1970. For example, 22\% married women aged 20-30 were employed in 1977, $1 \%$ were unemployed and $77 \%$ were inactive. In 1987, the rates were $30 \%, 13 \%$ and $57 \%$, respectively. In 1997, the proportions were $40 \%, 20 \%$ and $40 \%$.
} 
Table 6: Female's Unemployment rates: ${ }^{1}$ 1975-95

\begin{tabular}{l|ccccc}
\hline \hline & \multicolumn{5}{|c}{ Female Unemployment Rates } \\
\hline \hline Countries & 1975 & 1980 & 1985 & 1990 & 1995 \\
\hline Belgium & 7.5 & 13.8 & 18.9 & 12.5 & 14.0 \\
Germany & 5.4 & 5.2 & 10.4 & 8.4 & 9.2 \\
Italy & 6.3 & 10.8 & 17.7 & 15.0 & 15.2 \\
Spain $^{2}$ & $4.8^{3}$ & 10.2 & 25.7 & 24.2 & 30.9 \\
Sweden $^{3}$ & 2.0 & 2.3 & 2.9 & 1.6 & 6.9 \\
\hline \hline
\end{tabular}

${ }^{1}$ Source: Eurostat Employment and Unemployment.

${ }^{2}$ Source for Spain: INEBase.

${ }^{3}$ Data from 1976 in Spain.

${ }^{4}$ Source for Sweden: Statistiska Centralbyrån (Sweden).

Table 7: Country Comparison Transitions Employment vs. Non-Employment around $1^{\text {st }}$ Birth (from 1 year pre-birth to 2 years post-birth ${ }^{1}$ )

\begin{tabular}{l|ccccc}
\hline \hline Country & $n$ & $e-e^{2}$ & $e-n e$ & $n e-e$ & $n e-n e$ \\
\hline \hline Belgium & 1756 & $62.7 \%$ & $18.1 \%$ & $4.8 \%$ & $14.4 \%$ \\
West-Germany & 1222 & $31.5 \%$ & $37.2 \%$ & $4.7 \%$ & $26.6 \%$ \\
Italy & 2658 & $35.6 \%$ & $12.1 \%$ & $5.5 \%$ & $47.9 \%$ \\
Spain & 2297 & $27.6 \%$ & $19.3 \%$ & $5.4 \%$ & $47.8 \%$ \\
Sweden & 2063 & $51.1 \%$ & $26.8 \%$ & $8.2 \%$ & $13.9 \%$ \\
\hline \hline
\end{tabular}

${ }^{1}$ Excluding censoring.

2 e means Employment and ne means Non-Employment.

Belgium, $62.7 \%$ of first-birth mothers are employed pre and post-birth, which is the highest rate. As foreseen, Spain has the lowest with only $27.6 \%$ women at work at both times. $51.1 \%$ of Swedish women do not leave employment, which is consistent with the result of $46.7 \%$ found by Wetzels (1999). ${ }^{20}$ West-Germany and Italy have rates of being at work in the two periods of $31.5 \%$ and $35.6 \%$ respectively. Transitions from employment to non-employment are greater in Sweden, where 26.8\% mothers moved in this way, and in West-Germany, with $37.2 \%$. These results are similar to those found by Wetzels (1999). She estimates (using other data sources) transitions of $29.3 \%$ for Sweden and $41.9 \%$ for West-Germany (GSOEP 1983-92). Many of these women are on maternity leave and are accounted in Sweden as non-employed. The same might be partly the case for childcare leave in Germany. In the other countries, we observe that Spain has $19.3 \%$ women experiencing transitions to non-employment, Belgium $18.1 \%$ and Italy $12.1 \%$. Table 7 suggests that around half of mothers are out of work not only 12 months before the birth

\footnotetext{
${ }^{20}$ She looks at shifts between 3 months pre-birth and 24 months after.
} 
Table 8: Country Comparison Transitions Employment vs. Non-Employment around $1^{s t}$ Birth (from 1 year pre-birth to 5 years post-birth ${ }^{1}$ )

\begin{tabular}{l|ccccc}
\hline \hline Country & $n$ & $e-e^{2}$ & $e-n e$ & $n e-e$ & $n e-n e$ \\
\hline \hline Belgium & 1411 & $58.2 \%$ & $21.2 \%$ & $7.4 \%$ & $13.2 \%$ \\
West-Germany & 957 & $31.6 \%$ & $35.8 \%$ & $7.2 \%$ & $25.4 \%$ \\
Italy & 2337 & $32.7 \%$ & $14.2 \%$ & $9.5 \%$ & $43.6 \%$ \\
Spain & 1987 & $25.4 \%$ & $20.2 \%$ & $7.4 \%$ & $47.0 \%$ \\
Sweden & 1710 & $53.3 \%$ & $24.0 \%$ & $10.1 \%$ & $12.6 \%$ \\
\hline \hline
\end{tabular}

${ }^{1}$ Excluding censoring.

${ }^{2} e$ means Employment and ne means Non-Employment.

but also 24 months after in Italy and Spain. In Belgium and Sweden, women have highest employment rates 12 months before maternity. Although there are significant shifts to non-employment from previous employed women in these two countries, the percentage of mothers out of work in both pre and post-birth is only about $13 \%$. Germany is somewhere in between since $26.6 \%$ women do not work either before the birth nor after it.

We calculate the proportion staying-on at work. We find that $78 \%$ of Belgian mothers who worked 12 months before confinement are also employed 24 months after. The percentages are $46 \%$ in West-Germany, $75 \%$ in Italy, $59 \%$ in Spain and $66 \%$ in Sweden. The paper by Saurel-Cubizolles et al. (1999), which is focused on data from the midnineties, finds that $78 \%$ of recent mothers have come back to work in Italy when the baby is one year old. For West-Germany and Sweden, Wetzels (1999) obtains a return rate of $44 \%$ and $61 \%$ respectively. Although she selects women who were employed three months before confinement (we take a criterion of one year), her results are in line with ours. Since there is the possibility of childcare leave (especially in Sweden and West-Germany), we look also at transitions from one year pre-birth to five years post-birth in Table 8 . However, note that this includes women with more children, which makes it more difficult to interpret. We calculate the staying-on work rates over this period as $73 \%$ in Belgium, $47 \%$ in West-Germany, $70 \%$ in Italy, $56 \%$ in Spain and $69 \%$ in Sweden. Note that the returning rates to work after first birth have slightly risen in Sweden, compared to the transitions we had with our previous three years horizon. This confirms that Swedish women make use of their leave but come back to work afterwards. This also suggests that the possibility of more children has little impact on subsequent employment. The percentages for Belgium, Italy and Spain diminish around three percentage points. WestGermany staying-on rates remain fairly constant.

We would like to know if recent mothers choose part-time work. Table 9 shows the movements between full and part-time work among those women who remained employed. Swedish's preference for part-time work after birth is evident since about half of Swedish mothers moved from full-time to part-time job status. These shifts hardly exist in Spain and Italy, where only about 2-3\% move. $12.5 \%$ of Belgian mothers became new part-time 
Table 9: Country ${ }^{1}$ Comparison Transitions Full-time Employment vs. Part-time ${ }^{2}$ Employment around $1^{\text {st }}$ Birth (from 1 year pre-birth to 2 years post-birth)

\begin{tabular}{l|ccccc}
\hline \hline Country & $n$ & ef-ef & ef-ep & ep-ef & ep-ep \\
\hline \hline Belgium & 992 & $78.9 \%$ & $12.5 \%$ & $1.8 \%$ & $6.8 \%$ \\
West-Germany & 211 & $73.5 \%$ & $5.7 \%$ & $20.8 \%$ & $0.0 \%$ \\
Italy & 752 & $83 \%$ & $2 \%$ & $0.3 \%$ & $14.7 \%$ \\
Spain & 564 & $83 \%$ & $3.2 \%$ & $1.4 \%$ & $12.4 \%$ \\
Sweden & 1032 & $38.5 \%$ & $49.2 \%$ & $1.9 \%$ & $10.4 \%$ \\
\hline \hline
\end{tabular}

${ }^{1}$ West-Germany has high rate of missing information.

${ }^{2}$ Part-time if work less than 35 hours per week.

3 ef means Full-time Employment and ep means Part-time.

workers. Therefore, in Belgium and especially in Sweden, it is common to move to parttime positions after motherhood. This means two things: either the preferences of women are quite different across countries or flexibility and opportunity to transfer into part-time jobs is different. We think that the latter is more likely to be driving the result. Part-time does not seem to be related to motherhood in Spain and in Italy, whereas it definitely is in Belgium and Sweden. We believe that some Spanish or Italian women might opt for participation around childbearing if part-time jobs were commonly available.

\subsection{Is the Withdrawal from Work Due to Marriage or to Moth- erhood?}

We have seen that their employment rates indicate that Spanish mothers initiate their exit from employment far before the birth. The same is slightly visible for Italy. We would like to see if the fall in employment rates around childbearing is caused only by the birth itself or if, by contrast, marriage plays an important role. In order to do so, we take as a control group mothers without children and we observe their employment rates around the marriage date. In Figure 2, we compare Belgium, West-Germany, Italy and Spain. We observe that recently married women in Spain experience a decline in their employment rates. Italian employment rates also drop, although they seem to recover to some extent. Therefore, part of the decline in employment around childbearing may be explained by marriage. This shows evidence of these countries being more traditional. Note that at this stage we are pooling all cohorts. We would expect this effect to be lower in younger generations (for the same levels of unemployment). ${ }^{21}$ Belgian and German employment rates are not affected by marriage. Thus, their drop in employment rates around motherhood is due to the birth itself. Note that their employment rates even rise before marriage, meaning that they complete education, they find a job and then they marry.

\footnotetext{
${ }^{21}$ See Figure 8 in Appendix C.
} 
Figure 2: Employment Rates Before and After Marriage: Country comparison

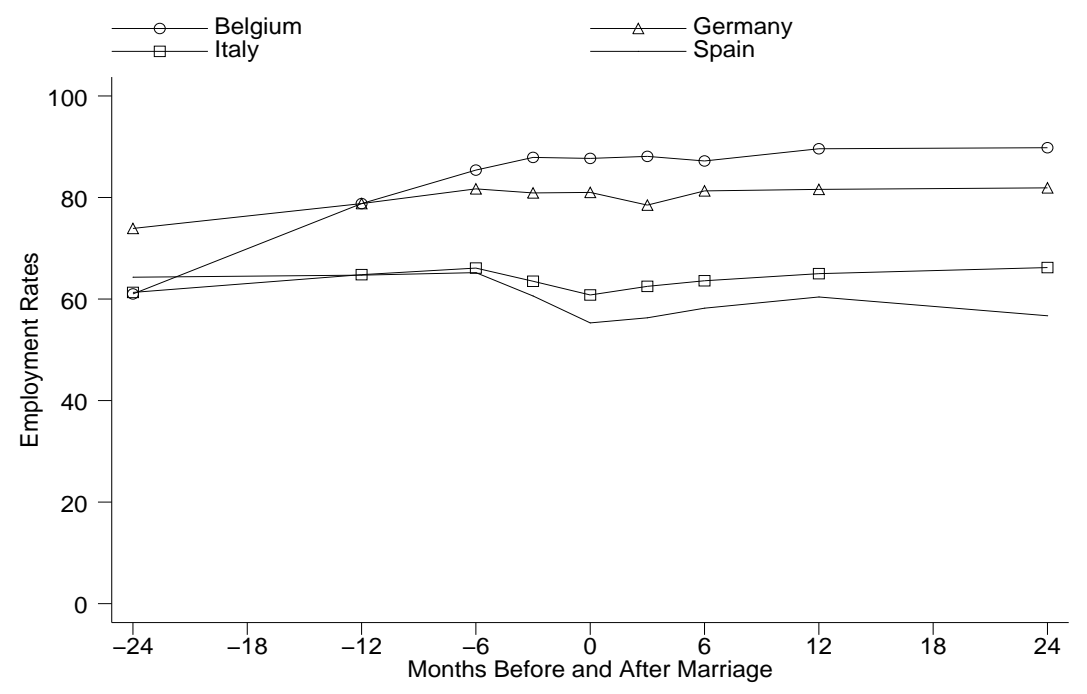

The purpose of Table 10 is to look at transitions between employment and non-employment around marriage for those women who do not have any child. Clearly, Spain (followed by Italy) is the country with the highest number of cases classified as employed 12 months before the marriage and non-employed 24 months after. Among those Spanish women who were employed before marriage, $71 \%$ are at work after. These rates are 94\%, 90\% and $71 \%$ for Belgium, West-Germany and Italy respectively.

Table 10: Country Comparison Transitions Employment vs. Non-Employment around Marriage (from 1 year pre-marriage to 2 years post-marriage ${ }^{1}$ )

\begin{tabular}{l|ccccc}
\hline \hline \multirow{2}{*}{ Country } & $n$ & $e-e^{2}$ & $e-n e$ & $n e-e$ & $n e-n e$ \\
\hline \hline Belgium & 285 & $70.9 \%$ & $4.2 \%$ & $18.9 \%$ & $6.0 \%$ \\
West-Germany & 198 & $68.7 \%$ & $7.6 \%$ & $19.9 \%$ & $10.1 \%$ \\
Italy & 266 & $55.3 \%$ & $12.4 \%$ & $10.9 \%$ & $21.4 \%$ \\
Spain & 164 & $47.0 \%$ & $18.9 \%$ & $9.8 \%$ & $24.3 \%$ \\
\hline \hline
\end{tabular}

\footnotetext{
${ }^{1}$ Excluding censoring.

2 e means Employment and ne means Non-Employment.
}

We would like to test if there have been cohort changes in employment rates around childbearing and marriage. Figure 8 in Appendix $\mathrm{C}$ represents employment rates around marriage by country and by cohort. We actually find that there are some cohort variations but these are only noteworthy in Spain. Despite the sample being rather small, there is evidence that Spanish married childless female employment rates from cohort 1945-54 experience a significant decline close to marriage. The proportion of employed women six months before marriage is $66.7 \%$, whereas the percentage is $37 \%$ afterwards. The respective rates are 65.2 and 62.3 for cohort $1955-64$. Thus, one would expect to have a smaller effect of marriage itself on the drop of employment around childbearing in younger 
generations. This generational evolution in employment rates around marriage is not as important in the other countries. ${ }^{22}$

\section{Model}

Our purpose is to determine how a woman's observed characteristics before her first birth affect her probability of working after the baby is born. We are interested in transitions from employment (12 months before the birth) to non-employment.

Mothers who were at work before the birth decide monthly after the birth if they participate in the labour market. They maximise their utility subject to their budget and time constraint (see Becker, 1993) for further details on family-labour supply models). For given preferences, family and taxation policies have an impact on the mother's budget (e.g subsidies for childcare) and time constraint (public available child-care or flexible ${ }^{23}$ hours), and these policies could make it more likely that women participate, ceteris paribus. Simultaneously, mothers who choose to be active are affected by job opportunities (i.e unemployment rates) that resolve if they are employed. These job opportunities also differ across countries. In our analysis, we estimate a reduced form for the employment after childbearing that embodies both the decision process and the economic situation.

In order to have a comparable sample, we use those cohorts and observable years that are common among our countries. These are cohorts $1951-1970,{ }^{24}$ and years up to $1993 .^{25}$ We estimate a probit model that takes into account the sample selection that arises from being employed or not before the birth. We first determine the characteristics that make it more likely to belong to the sub-sample of being at work before the birth and then the factors that determine that this sub-group is employed or not after the birth. In the selection equation we control for the unemployment rates in order to identify the model. In the restricted sample (women who were at work 12 months before childbearing) we have 1603 individuals for Belgium, 935 for West-Germany, 960 for Italy, 914 for Spain and 1783 for Sweden.

The main tool we use is the Latent Variable Model for Binary Variables. ${ }^{26}$ We observe a binary variable $E_{i t}$, which is a woman $i$ labour force participation at time $t$. This variable $E_{i t}$ can only be observed in two states: a woman is at work $\left(E_{i t}=1\right)$ or not $\left(E_{i t}=0\right)$. Nevertheless, not all women in the labour force are there with the same certainty. We suppose that there is an unobserved or so-called latent variable $E_{i t}^{*}$ that generates the observed $E_{i t}$ 's. Those women who have larger values of $E_{i t}^{*}$ are observed as $E_{i t}=1$, while

\footnotetext{
${ }^{22}$ We are surprised about the rather small cohort variation in Italy. We would have expected a closer pattern with respect to Spain.

${ }^{23}$ Notice that if women have full flexibility on the number of hours, they face a continuous time constraint. By contrast, if they must either work full-time or not work, they face a kink in the time constraint that could lead them to non-participation with higher probability.

${ }^{24} 1949-69$ for Sweden and 1952-70 for West-Germany.

${ }^{25}$ Notice that FFS's interviews are done between 1995-96 in Spain and Italy, which means that we observe individuals from equal cohort longer in these two countries. We artificially constrain their history up to 1993.

${ }^{26}$ We base our model description on Long (1997).
} 
those with smaller values of $E_{i t}^{*}$ are observed as $E_{i t}=0$. The idea of a latent $E_{i t}^{*}$ is that there is an underlying propensity to work that generates the observed state through the following measurement equation:

$$
E_{i t}=\left\{\begin{array}{lll}
1 & \text { if } & E_{i t}^{*}>\tau \\
0 & \text { if } \quad & E_{i t}^{*}<=\tau
\end{array}\right.
$$

where $\tau$ is the threshold.

The latent $E_{i t}^{*}$ is assumed to be linearly related to the observed characteristics $x_{i t}$ by the structural model:

$$
E_{i t}^{*}=x_{i t} \beta+\epsilon_{i t}
$$

Although we are not able to observe $E_{i t}^{*}$, a change in $E_{i t}^{*}$ results in a change in what we indeed observe, namely, whether a woman is at work at that time. Some characteristics, for example, the number of children in the household, will modify the woman's propensity to be employed as opposed to working at home. We would expect that a new birth will diminish the propensity to work up to a point to overcome a threshold that makes this woman decide to leave the labour force and stay at home.

Since $E=1$ when $E^{*}>0$ and $E^{*}=x \beta+\epsilon$,

$\operatorname{Pr}(E=1 \mid x)=\operatorname{Pr}\left(E^{*}>0 \mid x\right)=\operatorname{Pr}(x \beta+\epsilon>0 \mid x)=\operatorname{Pr}(\epsilon>-x \beta \mid x) .{ }^{27}$

We assume that our errors follow a normal distribution with $E(\epsilon \mid x)=0$, which result in the probit model. The normal distribution is symmetric, meaning that $\operatorname{Pr}(E=1 \mid x)=$ $\operatorname{Pr}(\epsilon<=x \beta \mid x)$. This is the cumulative density function of the error distribution evaluated at $x \beta$. Consequently,

$$
\operatorname{Pr}(E=1 \mid x)=\Phi(x \beta)
$$

These models permit us to compute how different explanatory variables affect the probability that an individual belongs to a particular status (categorical dependent variable). Here, the probit estimation has the target to determine the probability of a woman with certain characteristics being at work or not. Since we are interested in the evolution of a woman's career post-first-birth, we estimate a monthly probit ${ }^{28}$ from the moment of birth onwards.

If observations are independent, the general likelihood function of a probit model is:

$$
L(\beta / E, X)=\prod_{E=1} \Phi\left(x_{i} \beta\right) \prod_{E=0}\left(1-\Phi\left(x_{i} \beta\right)\right)
$$

$E$ is a random variable that takes value 1 if the individual is employed and 0 otherwise. In our probit, we have the following specification:

$$
L(\beta / E, X)=\prod_{E=1} \Phi\left(\alpha_{t} D_{t}+\sum_{k} \beta_{k} x_{k i t}\right) \prod_{E=0}\left(1-\Phi\left(\alpha_{t} D_{t}+\sum_{k} \beta_{k} x_{k i t}\right)\right)
$$

\footnotetext{
${ }^{27}$ We take the threshold $\tau$ as zero. There is no loss of generality here because the threshold is absorbed into the constant term.

${ }^{28} \mathrm{We}$ assume that the errors are normally distributed.
} 
$D_{t}$ is a matrix with 96 columns, one for each month after motherhood. ${ }^{29}$ For example, $D_{1}$ is a column vector that takes value 1 for each individual at the month one after birth and 0 otherwise. Similarly, $D_{2}$ takes value 1 at month 2 after confinement and 0 otherwise, and so on. $x_{k i t}$ is a vector of explanatory variable $k$ for each individual $i$ and time after birth $t$. $\beta_{k}$ is the vector of the coefficients of the explanatory variables and $\alpha_{t}$ is the vector with the coefficients of the time effects. If we maximise the log-likelihood of the previous expression, we will find the estimates for $\beta_{k}$ and $\alpha_{t}$. Note that we do not observe all individuals after first motherhood up to 96 months, which means that the contribution of each individual to the whole explanatory matrix does not have the same length. We are aware that observing individuals over a heterogenous period of time might produce misleading estimates because their may be a systematic relationship between period of stay in the sample and employment status. In order to check this, we re-estimate the same model and restrict the sample to those individuals who appear throughout the period (older individuals). After this restriction, we have 1062 observations in Belgium, 688 in West-Germany, 2056 in Italy, 1684 in Spain and 1410 in Sweden. Results (see Table 17 in Appendix B) are numerically similar to those estimated with the whole sample (Table 11).

To facilitate the interpretation of the results, we plot the predicted probability path of being at work for different representative individuals (called $R I$ ). The estimated probability of being employed at each month after first birth is given by the next expression, where we substitute our selected values for $x_{k R I t}$.

$$
\operatorname{Prob}(E=1)_{R I t}=\Phi\left(\hat{\alpha}_{t} D_{t}+\sum_{k} \hat{\beta}_{k} x_{k R I t}\right)
$$

For this exercise, we are also interested in analysing the evolution through time of the impact of education on employment after childbearing. We re-estimate our probit with interactions between $E 3 G r P o^{30}$ and our time dummies. We reduce the time dummies to $D_{3}, D_{6}, D_{12}, D_{24}, D_{48}$, and $D_{96}$. This means that we plot the probability of being employed at each of these post-birth periods.

Table 11 shows the marginal effects of the probability of employment after childbearing. We observe that the higher the level of education ${ }^{31}$ achieved pre-confinement, the more likely are mothers to remain employed after childbearing. Interestingly, education is significant in all countries except for Sweden, which means that Swedish mothers' employment after first birth is less affected by their differences in education. This result is in line with the paper by Gustafsson et al. (1996). They show that human capital is not a main determinant for re-entry in Sweden, whereas it is in Germany and Great Britain. Sweden is characterised by its generous public childcare provision, which means that many women

\footnotetext{
${ }^{29}$ We analyse post-birth labour force status up to 96 months after the confinement.

${ }^{30}$ Dummy (1 if highest education is university or post-graduate degree).

${ }^{31}$ It would be interesting to control for partner's education as a proxy for the effect of external income on female labour supply. However, partner's education is only available at the interview's date (not retrospectively). Although this could be a good proxy for Spain or Italy (where most women are married when childbearing and there are few divorces), it is not for Sweden or West-Germany. In Gutiérrez-Domènech (2002), we control for partner's education and find that Spanish women whose partner have medium education are less likely to work after childbearing, ceteris paribus, compared to those whose partners have no qualifications. However, mothers with graduate husband's are more likely to be employed.
} 
Table 11: Probability of Employment After $1^{\text {st }}$ Birth: following 96 Months

\begin{tabular}{|c|c|c|c|c|c|}
\hline \multirow[t]{2}{*}{ Variables } & \multicolumn{5}{|c|}{ Probit After $1^{\text {st }}$ Birth: Marginal Effects ${ }^{1,2}$} \\
\hline & Belgium & W-Germany & Italy & Spain & Sweden \\
\hline City $^{3}$ & $-0.082^{* *}(0.036)$ & $-0.011(0.021)$ & $0.023(0.024)$ & $0.030(0.043)$ & $-0.009(0.024)$ \\
\hline Religious & $-0.084^{* *}(0.030)$ & $-0.023(0.022)$ & $-0.069^{*}(0.039)$ & $-0.044(0.062)$ & $0.004(0.019)$ \\
\hline Married $1 C$ & $0.043(0.058)$ & $-0.082^{* *}(0.030)$ & $-0.014(0.042)$ & $-0.047(0.055)$ & $-0.036^{*}(0.020)$ \\
\hline Experience $^{4}$ & $0.007^{* *}(0.002)$ & $0.012^{* *}(0.002)$ & $0.003^{* *}(0.0005)$ & $0.001^{*}(0.0007)$ & $0.002^{* *}(0.0006)$ \\
\hline AgeAt1Job & $0.069^{* *}(0.018)$ & $0.129^{* *}(0.019)$ & $0.031^{* *}(0.006)$ & $0.004(0.006)$ & $0.027^{* *}(0.008)$ \\
\hline AgeAt1C & $-0.018(0.049)$ & $-0.045(0.038)$ & $-0.057(0.027)$ & $-0.003(0.048)$ & $0.064(0.040)$ \\
\hline AgeAt1C2 & $-0.0009(0.0009)$ & $-0.001^{* *}(0.006)$ & $-0.001(0.0005)$ & $-0.0001(0.0009)$ & $-0.002^{* *}(0.0006)$ \\
\hline Education $^{5}$ & & & & & \\
\hline E2 & $0.036(0.034)$ & $0.117^{* *}(0.046)$ & $0.079^{* *}(0.027)$ & $0.108^{* *}(0.051)$ & $0.009(0.071)$ \\
\hline E3 Voc & $0.131^{* *}(0.040)$ & $0.207^{*}(0.112)$ & & $0.248^{* *}(0.101)$ & \\
\hline E3GrPo & $0.193^{* *}(0.041)$ & $0.225^{* *}(0.111)$ & $0.074(0.050)$ & $0.256^{* *}(0.111)$ & $0.028(0.070)$ \\
\hline Cohorts $^{6}$ & & & & & \\
\hline $1954^{7}$ & & & & & $-0.0003(0.081)$ \\
\hline $1956-60^{8}$ & $0.008(0.037)$ & $0.015(0.040)$ & $-0.004(0.030)$ & $-0.014(0.057)$ & $-0.004(0.157)$ \\
\hline $1961-65^{9}$ & $0.023(0.063)$ & $0.072(0.074)$ & $-0.006(0.046)$ & $-0.053(0.104)$ & $-0.041(0.229)$ \\
\hline $1966-70^{10}$ & $-0.021(0.108)$ & $-0.003(0.104)$ & $-0.076(0.062)$ & $-0.248^{*}(0.159)$ & $-0.103(0.294)$ \\
\hline
\end{tabular}

* Significant at $10 \%$ level.

** Significant at $5 \%$ level.

${ }^{1}$ Standard errors in brackets.

${ }^{2}$ Time dummies, year dummies and interactions not reported. They are available upon request.

${ }^{3}$ Dummy (1 if individual's locality up to 15 had $>=100.000$ inhabitants).

${ }^{4}$ Accumulated number of months worked up to the birth.

${ }^{5}$ Omitted category is the lowest level $(E 1)$.

${ }^{6}$ Omitted category is Cohort 1951-55 (Cohort 1952-55 for West-Germany and Cohort 1949 for Sweden).

${ }^{7}$ Cohort 1954 for Sweden only.

${ }^{8}$ Cohort 1959 for Sweden.

${ }^{9}$ Cohort 1964 for Sweden.

${ }^{10}$ Cohort 1969 for Sweden.

Note: Standard errors adjusted for clustering.

do not face the burden of childcare costs. By contrast, mothers in the other countries who decide to keep on employed must pay private nursery. Without public childcare, only those women with high earnings (or education here) will be able to afford childcare in order to stay-on employed. Consequently, high education is a key determinant for post-birth employment in countries with poor governmental childcare provision. Accumulated experience (i.e. number of months worked up the birth) increases considerably the chances of returning to work. Simultaneously, those mothers who initiated their first job later have a greater probability of post-birth employment. Our sociological factors report that religious women are less likely to return, ceteris paribus, in all countries, particularly 
in Belgium and Spain. The size of the city where the individual grew up impacts negatively on the probability of post-birth employment all countries, except in Italy and Spain.

Until now we have made no attempt to separate out the effect of future fertility patterns on post-birth employment from other more direct effects. Thus, variables influencing post-first birth employment can operate either directly or via their impact on subsequent fertility. To give some idea of the implications, we estimate the probability of employment after first birth only for those women who remain with one child. Of course, this means we are selecting a sub-sample based on a variable which may be endogenous to employment. Nevertheless, the subsequent results will still be informative. The number of observations is 663 in Belgium, 574 in West-Germany, 965 in Italy, 711 in Spain and 600 in Sweden. Table 18 in Appendix B shows the results for this sub-sample. With this new estimation, we observe that religion loses generally the negative impact that it had in the estimation with the whole sample. This suggests that religion effect is operating via its impact on future fertility. The coefficients on the remaining characteristics change little but both estimations differ substantially in the duration and calendar year dummies.

\section{Simulation}

In this section we focus on two issues. First, we are interested in whether the probability of post-birth employment has experienced variations in time within each country. For instance, do mothers in 1990 have a greater probability of post-birth employment than their counterparts in 1973? Second, we would like to take a representative individual and observe her probability of post-birth employment, given that she is mother in Belgium, West-Germany, Italy, Spain or Sweden. ${ }^{32}$

For the first exercise, we take an average individual and we compare the predicted probabilities of employment in three years: 1973, 1983 and 1993. In Figure 3, mother's have a secondary degree, whereas in Figure 4 they have a graduate or post-graduate degree. The rest of the women's characteristics are the same. Figure 3 reveals that the likelihood of being employed has changed differently across time in these countries. Belgian mothers whose highest school completion was a secondary degree experience a rise between 1983 and 1993. Interestingly, Spanish women's predicted employment increase significantly between 1973 and 1983. By contrast, the probability of post-birth employment has declined

\footnotetext{
${ }^{32}$ We are aware that the coefficients of each variable for a specific country might reflect not only the country-specific impact of that variable on the staying-on-rates but also other country-specific effects not controlled for in the model. Then, we could interpret that a particular variable affects differently post-birth employment in two countries but this is partly due to the coefficients being misleading. That is, if there are characteristics not included in the model that are correlated to an included variable, the coefficients of the included one will be bias. This will be captured in the error term and will produce endogeneity. To decrease the magnitude of this potential problem, we control for year calendar dummies. They account for all the common effects to all individuals in the country and hopefully eliminate the size of error and its link to other included variables. Then, the bias is eliminated and country comparison is more reliable. Notice, however, that this still does not control for certain specific effects that are related to some particular individuals. Ideally, we should incorporate interactions between the year calendar dummies and the other characteristics. We decide not to do this because it would require many variables for the number of observations we have.
} 
over time in West-Germany and has remained fairly constant in Italy and Sweden. We observe in Figure 4 that the chances of being employed after childbearing among Belgian, Italian and Swedish graduates and post-graduates women hardly increased in time. These graphs show evidence that the shift in predicted individual employment after childbearing in Belgium has been greater for the group of secondary degree women. That is, although mothers with a complete university degree are still much more likely to return to work, mothers with a lower education degree increased their probabilities with higher speed. In Spain, mothers with a university degree augment their chances of coming back in a similar proportion to those with a secondary degree. The pattern is different in West-Germany, where the shifts in time in post-birth predicted employment are similar between graduate and secondary school levels and occur in the opposite direction (downwards). In West-Germany, graduate women are more likely to be at work after childbearing but the variation in time has been equal for these two educational groups, which experienced a decline in post-birth employment. As shown in Table 11, graphs reveal that graduate Swedes have greater probability of post-birth employment but this is not significantly different from mothers with a secondary degree. Italian mother's who were at work before the birth with at least a graduate degree have a predicted post-birth employment rate of 90-100\%. ${ }^{33}$ We observe that there has been important changes in the estimated probability of employment after childbearing across years and countries. We will explore this variation in Section 7.

Figure 3: Monthly Probability of being Employed after $1^{\text {st }}$ Birth Conditional on Being Employed 12 Months Before: Mothers with Secondary Degree

Years and Country Comparison
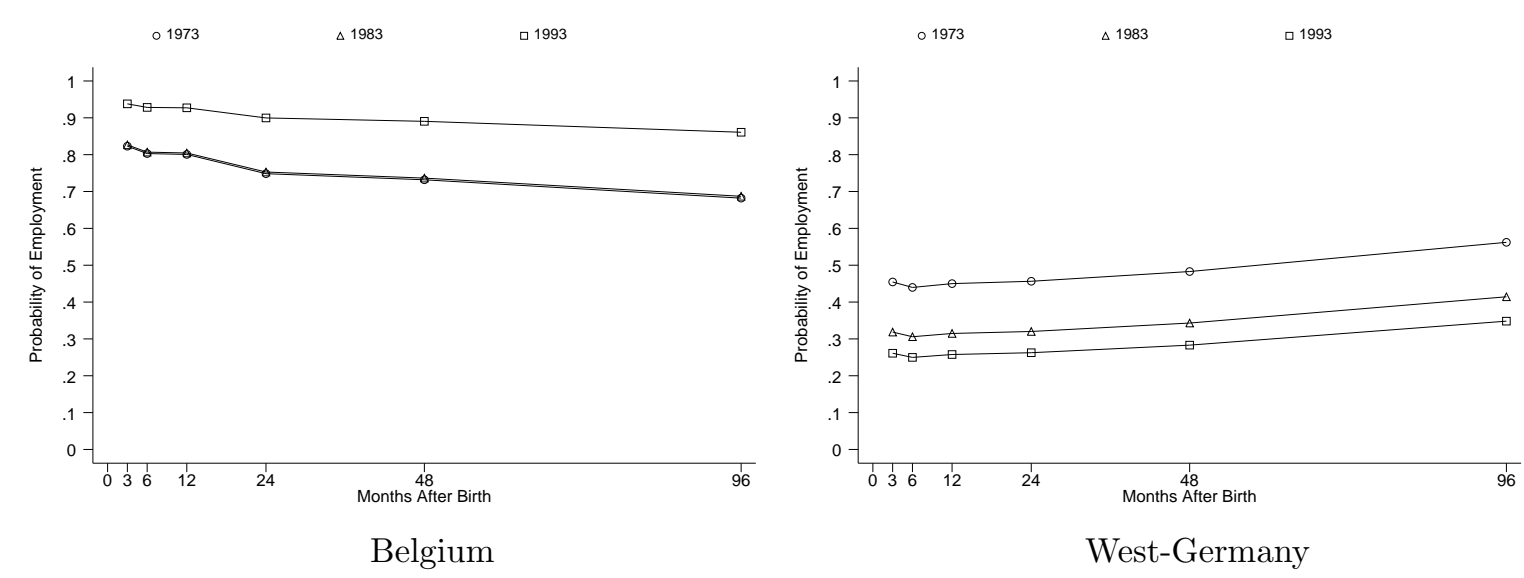

\footnotetext{
${ }^{33}$ We have also calculated the probability of being employed after childbearing without conditioning the sample to those mothers who were at work before the birth in the selection equation. This predicted post-birth employment rate for Italy is much lower. This implies that in Italy it is crucial to be employed before the birth in order to be employed after. Italy is the country where we observe that this effect is the largest.
} 

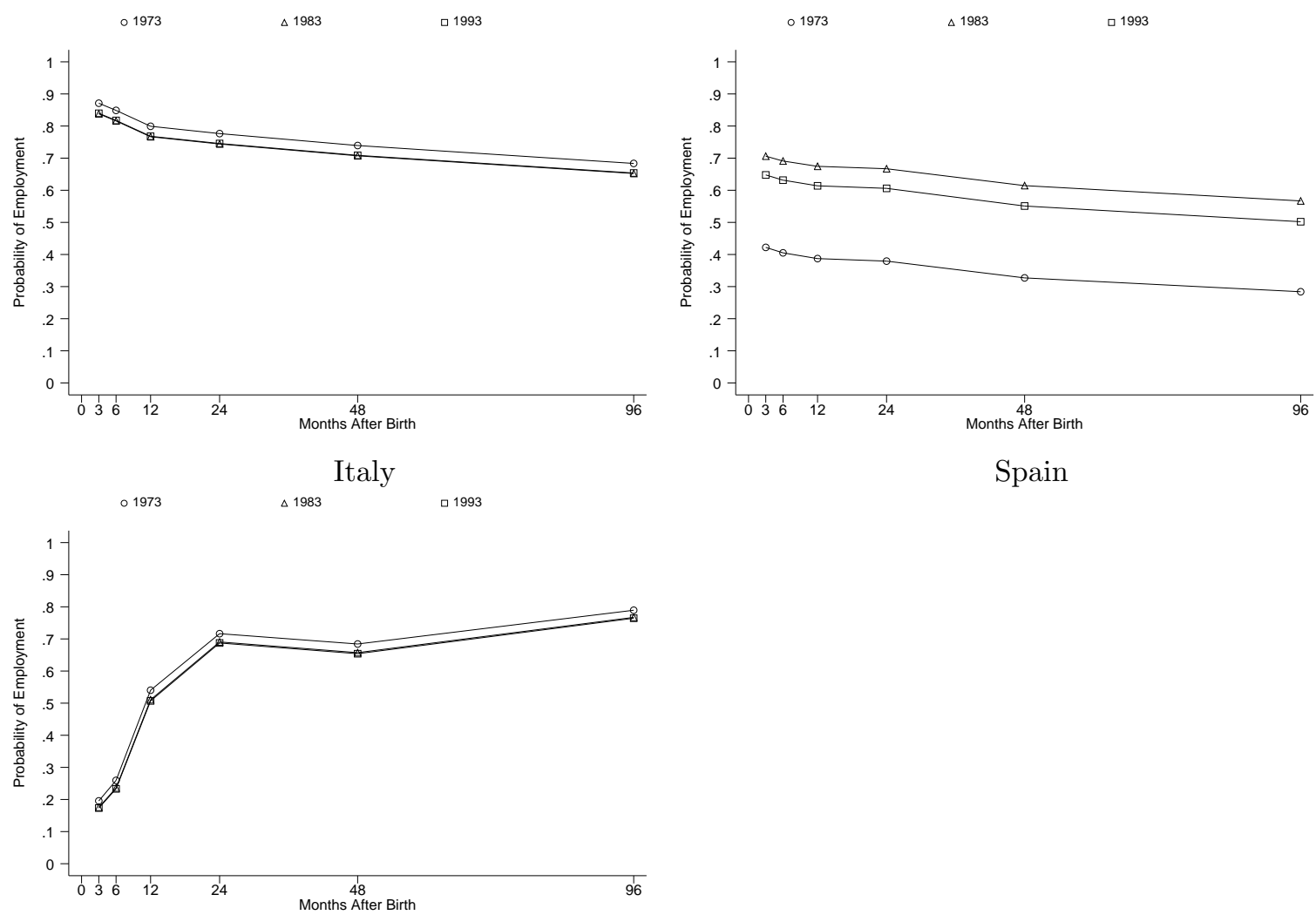

Sweden

Note: Swedish mothers are reporting to be non-employed when they are on maternity leave. This explains the huge drop of employment after childbearing.

Figure 4: Monthly Probability of being Employed after $1^{\text {st }}$ Birth Conditional on Being Employed 12 Months Before: Mothers with Graduate or Post-graduate Degree

Years and Country Comparison

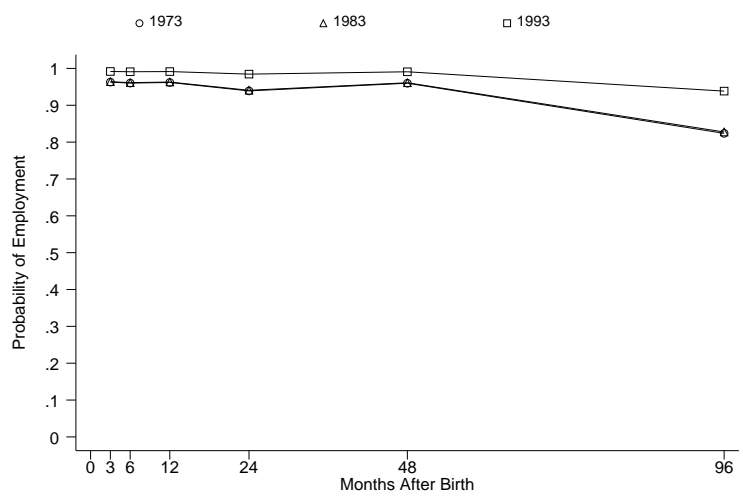

Belgium

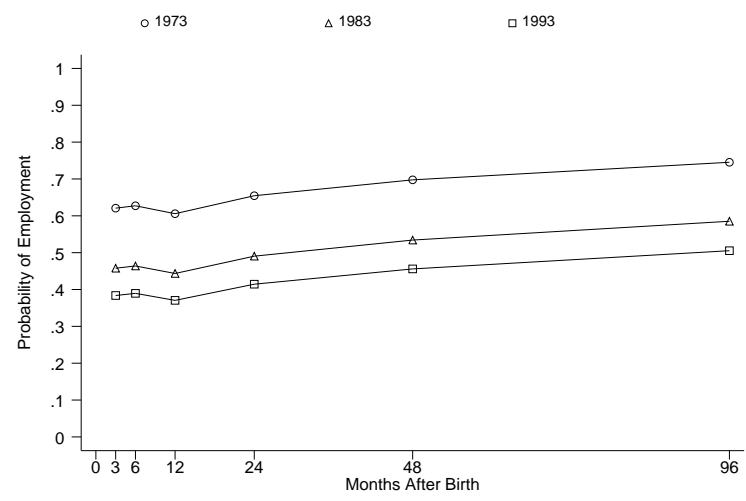

West-Germany 

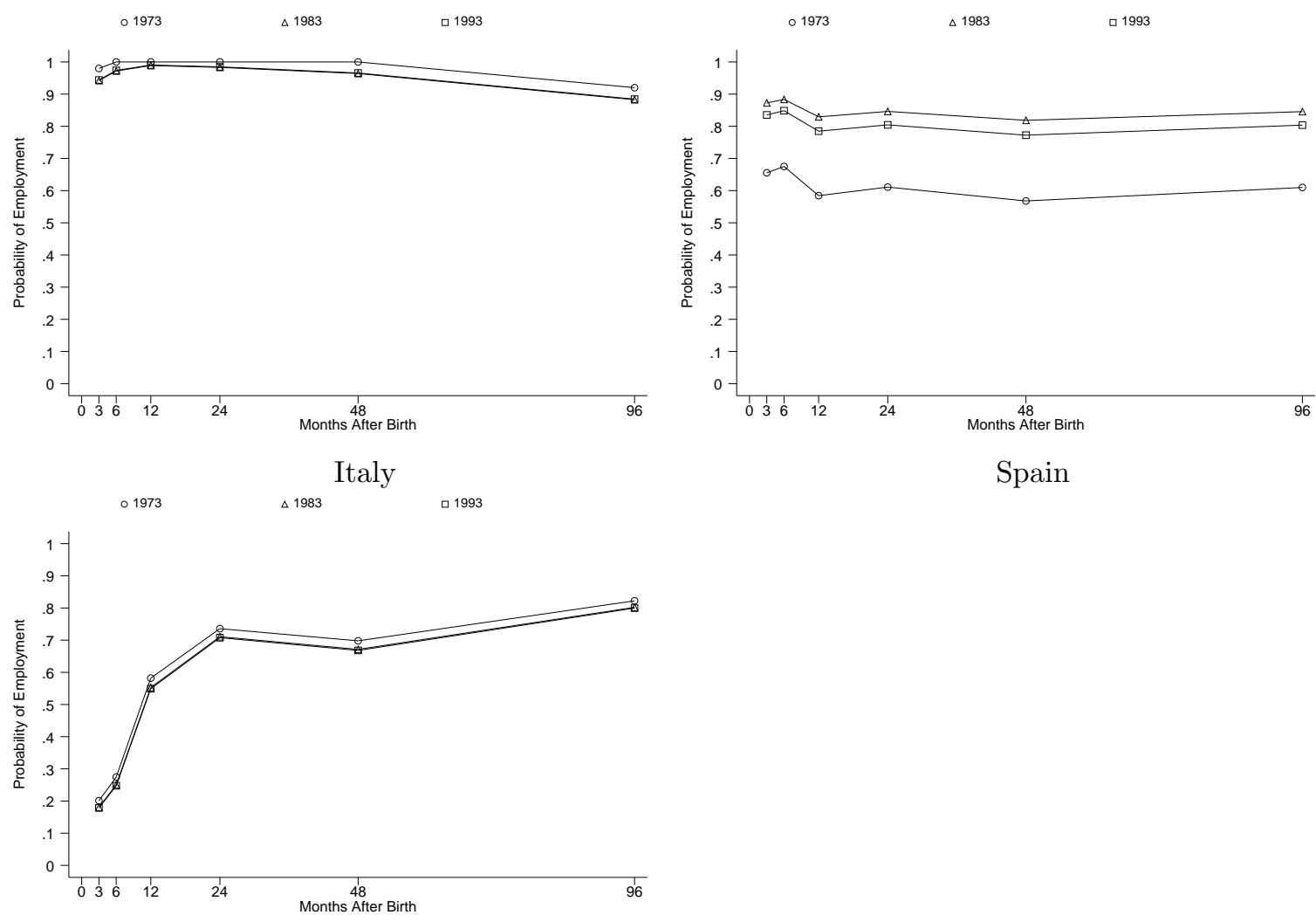

Sweden

Note: Swedish mothers are reporting to be non-employed when they are on maternity leave. This explains the huge drop of employment after childbearing.

Figure 5: Monthly Probability of being Employed after $1^{\text {st }}$ Birth Conditional on Being Employed 12 Months Before: Mothers with Secondary Degree

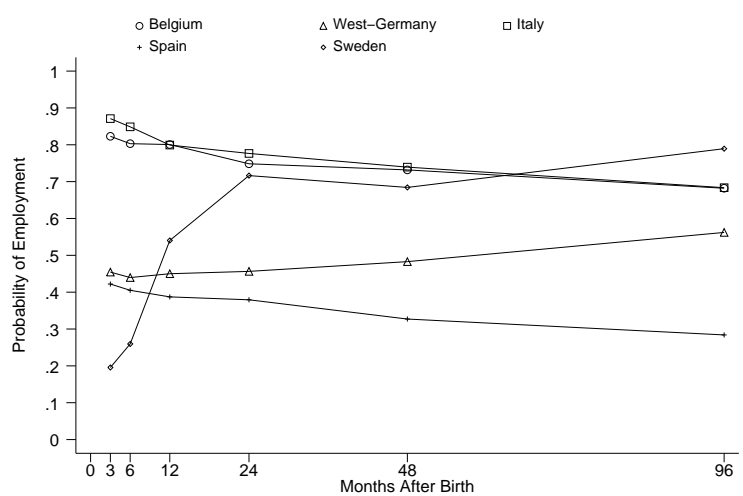

1973

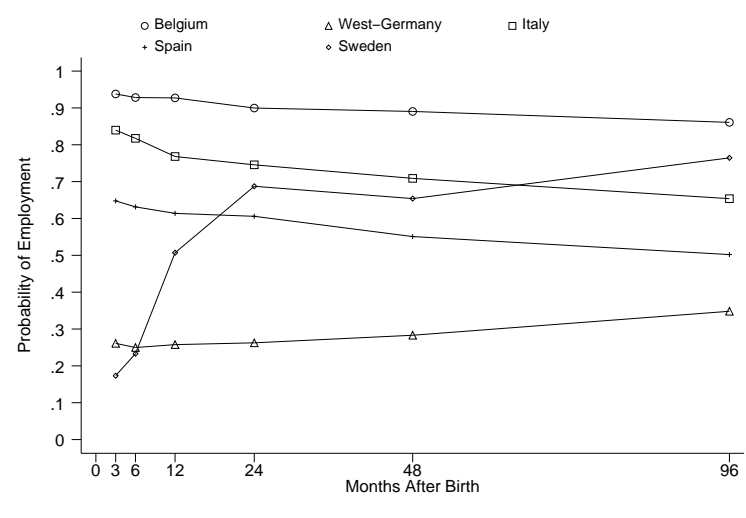

1993

Note: Swedish mothers are reporting to be non-employed when they are on maternity leave. This explains the huge drop of employment after childbearing. 
For our second exercise, Figure 5 compares the predicted post-birth employment rates across countries for women with a secondary degree in 1973 and 1993. Notice that Spain is the only country to experience a large shift upwards. Thus, Spain has had a clear change in behaviour within 1973-93. The forecast of being employed after childbearing decrease with post-birth time in Belgium, Italy and Spain. This may be due to the enlargement of families, which impacts negatively on female's participation. By contrast, both German and Swedish women's employment is predicted to rise with post-birth time. We are surprised about the low forecast levels of employment after childbearing in West-Germany and their decline in latter periods. However, as reported by Ondrich et al. (1996), 'since 1979 German federal maternity leave and benefit policy has given women incentives to stay at home and take care of their newborn and youngest children. In 1986 this leave and benefit policy was changed in several ways, turning it into a powerful instrument for delaying a mother's return to work after childbirth'. In their paper, they show evidence that the rise in the generosity of maternity leave has had the effect that mothers interrupt their careers for longer periods. This could also explain our results.

Figure 6 replicates Figure 5 for those women who had only one child. ${ }^{34}$ We observe that in Belgium the declining trend in the predicted probability of employment after first birth disappears slightly when we base our analysis on single child women. This makes sense since drops in employment after first birth are likely to be caused by more births. However, in Belgium, there seems not to be much difference between those mothers who only ever had one child and the whole sample of mothers, especially in 1993. In West-Germany, the post-birth time profile does not vary but, in both 1973 and 1993, the probabilities increase by about $20 \%$ and $10 \%$ respectively for all post-birth periods in the sample of single child mothers. Italian mothers with only one child ever have a slight increase on post-birth employment in 1993. ${ }^{35}$ compared to the whole group. This suggests that extra children in 1993 do not have a big negative impact on post-birth employment in Italy. Sweden experiences a parallel upwards shift in 1973 for the restricted sample of single mothers, although this disappears in 1993. Spanish single mothers have a post-birth employment rate around 30\% greater than the whole group of mothers in 1973 . The gap is $15 \%$ in 1993. This suggests that in Spain in 1973 there are two groups. One, who have only one child and are more committed to the job market; the other group have more than one child and are substantially less committed. This effect is reduced in 1993. Note that the distinction between single child mothers and all mothers is more muted in the other countries.

\footnotetext{
${ }^{34}$ Notice that the sample restricted to single child ever mothers is likely to have a higher proportion of young cohorts compared to the whole sample since they are more likely to have only one child so far.

${ }^{35}$ We are not able to interpret the result for Italy in 1973.
} 
Figure 6: Monthly Probability of being Employed after $1^{\text {st }}$ Birth Conditional on Being Employed 12 Months Before: Mothers with Secondary Degree (Women who Only Had One Child Ever)

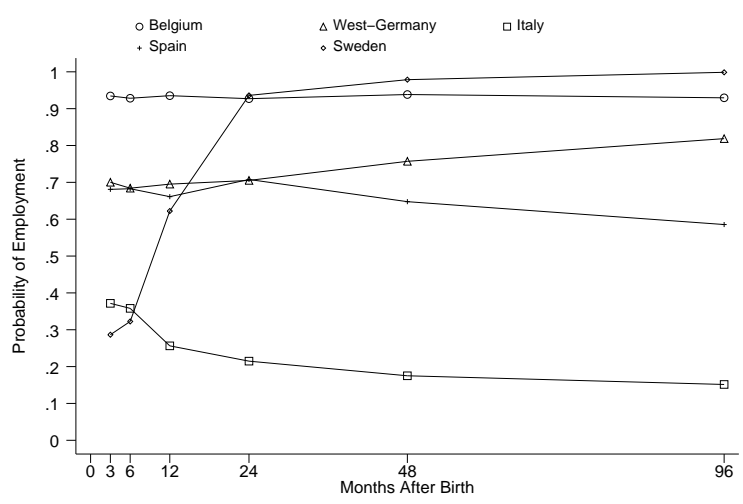

1973

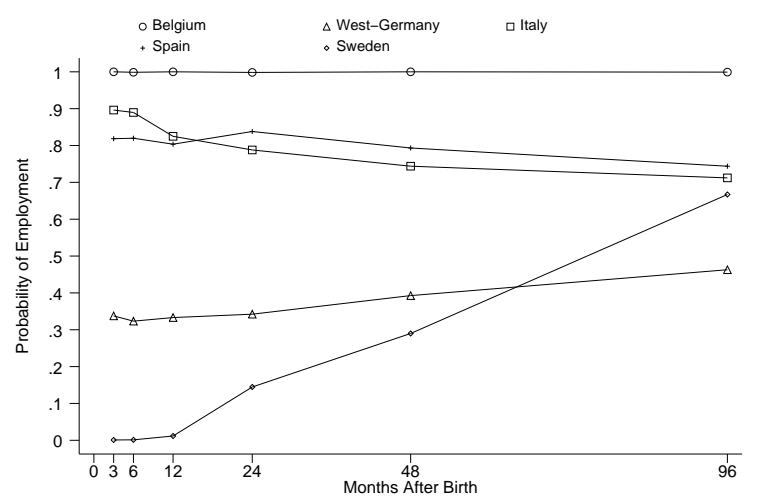

1993

Note: Swedish mothers are reporting to be non-employed when they are on maternity leave. This explains the huge drop of employment after childbearing. Year 1988 for Sweden.

\section{Policy Evaluation}

We would like to explain the impact of benefit policies and the labour market on the observed changes in post-birth employment across countries and years. We take the year dummy coefficients obtained in the probit estimation of employment after childbearing for each country and regress them on some potential explanatory variables. These are: the proportion of women who completed tertiary education $(F H E),{ }^{36}$ a constructed maternity leave indicator (Leave), ${ }^{37}$ a dummy accounting for the taxation system $($ Tax $),{ }^{38}$ female unemployment rates (Unemrf), the proportion of female part-time labour (FvsP), country dummies and a linear trend. ${ }^{39}$ We focus on the period 1982-93. Table 12 shows that the education, the proportion of female part-time and the taxation system are the main factors that explain the variation in time of post-birth employment. ${ }^{40}$ We observed in Section 6 that Spanish women experienced a rise in post-birth predicted employment.

\footnotetext{
${ }^{36}$ We use the Barro-Lee data set.

${ }^{37}$ This variable is calculated as follows: (number of weeks in maternity leave*replacement rates) + (number of weeks in childcare leave*replacement rates).

${ }^{38}$ The dichotomous is one if the country has a separate taxation system in a particular year and zero if it has a joint one.

${ }^{39}$ Year dummies have been used instead of a linear trend with the same results for the rest of the variables.

${ }^{40}$ We estimated the same equation with a broader interval of time 1973-93. The proportion of females with tertiary education and separate taxation had also a positive impact on the increase in re-entry in employment after childbearing. Unemployment rates were negative and significant, which we believe that it is due to its flatness pre-1982. Since education and taxation have a strong effect no matter how broad the period is considered, we are confident that these are the main explanatory factors to the variability of post-birth employment across time.
} 
Table 12 suggests this could be due to the increase in the proportion of women with tertiary education. This country has also moved into a separate taxation in 1989. By contrast, West-Germany remains under a joint taxation, which reduces the incentive for married mothers to work. There is evidence that separate taxation has a positive impact on post-birth employment. Finally, there is also some evidence that the proportion of part-time work has had a positive impact, most likely for Belgian mothers with secondary degree.

Table 12: OLS Regression of Probit Year-Country Dummies Estimates on Policies, Labour Market, Country dummies and Linear Trend

\begin{tabular}{l||cc}
\hline \multicolumn{1}{l||}{ Model } & \multicolumn{2}{c}{ OLS } \\
\hline \hline & \multicolumn{2}{c}{ All Sample } \\
\hline \hline & Coefficient & Std.Error \\
\hline FHE $^{1}$ & $23.838^{* *}$ & 6.086 \\
Leave $^{2}$ & -0.042 & 0.027 \\
Tax $^{3}$ & $0.108^{* *}$ & 0.050 \\
Unemrf $^{4}$ & 0.889 & 0.709 \\
FvsP $^{5}$ & $1.878^{* *}$ & 0.674 \\
\hline West-Germany & $0.931^{* *}$ & 0.372 \\
Italy & $1.258^{* *}$ & 0.299 \\
Spain & $2.030^{* *}$ & 0.251 \\
Sweden & 0.899 & 0.972 \\
\hline Linear Trend & $-0.041^{* *}$ & 0.010 \\
Cte & $1.795^{* *}$ & 0.510 \\
\hline \hline R-squared & \multicolumn{2}{|c}{0.98} \\
\hline \hline N observations & \multicolumn{2}{|c}{55} \\
\hline \hline
\end{tabular}

*Significant at $10 \%$ level.

** Significant at $5 \%$ level.

${ }^{1}$ Proportion of female with completed tertiary education.

${ }^{2}$ Constructed maternity leave indicator.

${ }^{3}$ Dummy: 1 if separate taxation system; 0 if joint.

${ }^{4}$ Proportion of female unemployment.

${ }^{5}$ Proportion of female in part-time positions.

${ }^{6}$ Country omitted category is Belgium. 


\section{Conclusions}

In this paper we focus on the transitions from employment to non-employment after motherhood in five countries: Belgium, West-Germany, Italy, Spain and Sweden. We observe cohorts born between 1951 and 1970. We use the same data source for each country in order to develop a comprehensive analysis of the main individual and institutional factors that determine employment after motherhood. We also estimate the probability stay on employment after childbearing and how this has evolved across time. Our main purpose is to understand the differences between countries.

From our comparison, we find that Spain and West-Germany are the countries with by far the highest decline in employment rates after first child. Our staying-on rates confirm the view that West-German employed women are strongly affected by first-birth. We find that of those mothers who were employed one year before first birth, only $46 \%$ are at work two years afterwards. The proportions are $78 \%$ in Belgium, $75 \%$ in Italy, $66 \%$ in Sweden and $59 \%$ in Spain. Although the staying-on rates on a two-year horizon are not much apart in Spain and Sweden, they differ in two main aspects. First, Swedish mothers have higher pre-birth employment rates. Second, Spanish drops are permanent rather than temporary. This means that once the procreation process is finished, more Swedish mothers are at work.

From those women who are employed both before and after confinement, we observe that there are noticeable differences across countries in terms of transitions full-time vs. parttime. In Belgium, 12.5\% women move from full-time to part-time after the birth of a first child. The rate is $49.2 \%$ in Sweden. Only about 3\% do in Italy and Spain, and $5 \%$ in West-Germany. We believe that this reflects disparity in the free choice of the number of working hours, rather than these countries being apart in female preferences. The lesson is that post-birth employment rates would be higher in West-Germany, Italy and Spain if mothers were offered broader flexibility to combine childcare and work part-time. That is, we might have more mothers moving into part-time employment instead of into inactivity.

In our probit estimation, we observe that women with graduate degrees are more likely to be at work after childbearing in all countries, except for Sweden. In the latter, education does not significantly raise the chances of post-birth employment. We also find that the number of months worked up to motherhood increase the probability of being employed after first birth. Thus, the accumulation of human capital increases the probability of post-birth employment.

A representative mother who was at work before the birth has a different predicted postbirth probability of employment depending upon the country where she lives. There are also relevant changes across years. Belgian and especially Spanish mothers increased their probability of post-birth employment, ceteris paribus. The opposite movement occurred in West-Germany; Italy and Sweden remained fairly constant.

The paper attempts to separate out the effect of future fertility patterns on post-birth employment from other more direct effects. We do this by estimating the probability of employment after first birth for those women who remain with one child. This reveals 
that in Spain (especially in earlier years) there are two different groups of mothers. One that have only one child and are committed to the job market; the other have more than one child and are less attached to it. This distinction is more muted in the other countries.

We observe that the predicted probability of being at work varies substantially across countries and years. We then explore the factors that could have caused this. That is, we look for aggregate variables that changed within this period, which are potentially related to mothers' employment. We find that the increase in completed female tertiary education, the separate taxation system and the proportion of part-time contracts consistently explain the observed changes. This is important for policy. For instance, West-Germany might experience an increase in post-birth employment if it moved into a separate taxation regime. Results also show that maternity leave does not significantly impact on post-birth employment. Note that all these countries have the right of reinstatement in the period 1973-93 but they differ in its generosity and length. We believe that a too long period of leave is counterproductive since it postpones return, which reduces female skills and might further disincentive re-entry. The availability of long maternity leave should be accompanied by public offered childcare (as in Sweden) or childcare tax relief (as in Belgium) so that women have the simultaneous choice of being at work and/or on leave. Besides, childcare should be flexible and accommodate mothers' needs in their working time. 


\section{References}

Adam, P. (1996a), Labour Force Transitions of Married Women in Spain, PhD thesis, European University Institute.

Adam, P. (1996b), Mothers in an Insider-Outsider Economy: The Puzzle of Spain, Journal of Population Economics 9, 301-323.

Apps, P. and Rees, R. (2001), Fertility, Female Labor Supply and Public Policy, IZA. Discussion Paper 409.

Beblo, M. and Wolf, E. (2002), The Wage Penalties of Heterogenous Employment Biographies: An Empirical Analysis for Germany, Centre for European Economic Research.

Becker, G. (1993), A Treatise on the Family, Harvard University Press.

Bernhardt, E. M. (1986), Women's Home Attachment at First Birth, European Journal of Population 2, 5-29.

Bernhardt, E. M. (1988), The Choice of Part-time Work among Swedish One-child Mothers, European Journal of Population 4, 117-144.

Del Boca, D. (2002), The Effect of Child Care and Part-time Opportunities on Participation and Fertility Decisions in Italy, IZA. Discussion Paper 427.

Desai, S. and Waite, L. J. (1991), Womens Employment During Pregnancy and After the First Birth: Occupational Characteristics and Work Commitment, American Sociological Review 56(4), 551-566.

Dex, S., Joshi, H., McCulloch, A. and Macran, S. (1996), Women's Employment Transitions Around Childbearing, Centre for Economic Policy Research. Discussion paper 1408.

Ellingsaeter, A. L. and Ronsen, M. (1996), The Dual Strategy: Motherhood and the Work Contract in Scandinavia, European Journal of Population 12, 239-260.

Gauthier, A. H. (2000), Public Policies Affecting Fertility and Families in Europe: A survey of the 15 Member States, Paper presented at the European Observatory on Family Matters, Sevilla (Spain), September 2000.

Gustafsson, S., Wetzels, C. and Vlasblom, J. (1996), Women's Labor Force Transitions in Connection with Childbirth: A Panel Data Comparison between Germany, Sweden and Great Britain, Journal of Population Economcs 9, 224-246.

Gutiérrez-Domènech, M. (2002), Employment Penalty After Motherhood in Spain, Centre for Economic Performance, working paper 1177.

Hank, K. and Kreyenfeld, M. (2000), Does the Availability of Childcare Influence the Employment of Mothers? Findins from Western Germany, MPIDR, working paper 2000-003. 
Kravdal, Ø. (1992), Forgone Labor Participation and Earning Due to Childbearing Among Norwegian Women, Demography 29(4), 545-563.

Long, J. S. (1997), Regression Models for Categorical and Limited Dependent Variables, SAGE Publications.

Moss, P. and Deven, F. (1990), Parental Leave: Progress or Pitfall? Research and Policy Issues in Europe, NIDI/CBGS.

OECD (1993), Taxation in OECD Countries, OECD.

OECD (2001), Balancing Work and Family Life: Helping Parents into Paid Employment, OECD Employment Outlook.

Ondrich, J., Spiess, C. K. and Yang, Q. (1996), Barefoot and a German Kitchen: Federal Parental Leave and Benefit Policy and the Return to Work After Childbirth in Germany, Journal of Population Economics 9, 247-266.

Rönsen, M. and Sunström, M. (1996), Maternal Employment in Scandinavia: A Comparison of the After-Birth Employment Activity of Norwegian and Swedish Women, Journal of Population Economics 9, 267-285.

Sainsbury, D. (1994), Gendering Welfare States, Sage London.

Saurel-Cubizolles, M. J., Romito, P., Escribà-Agüir, V., Lelong, N., Pons, R. M. and Ancel, P.-Y. (1999), Returning to Work After Childbirth in France, Italy and Spain, European Sociological Review 15, 179-194.

Tietze, W. and Cryer, D. (1999), Current trends in European early child care and education, Annals, AAPSS.

Wetzels, C. (1999), Squeezing Birth into Working Life. Household Panel Data Analyses comparing Germany, Great Britain, the Netherlands and Sweden, PhD thesis, Tinbergen Institute Research Series. Universiteit van Amsterdam. 


\section{A Labels for the variables}

Table 13: FFS Variable Labels

\begin{tabular}{ll}
\hline \hline Experience & Accumulated number of months worked up to the birth \\
Unemrf & Female regional unemployment Rates \\
AgeAt1C & Age at first child in years \\
AgeAt1C2 & Square of age at first child \\
AgeAt1Job & Age at first job \\
Married1C & Dummy (1 if married at first birth) \\
E1 & Dummy (1 if highest education is primary degree; omitted category) \\
E2 & Dummy (1 if highest education is secondary degree) \\
E3Voc & Dummy (1 if highest education is vocational tertiary degree) \\
E3GrPo & Dummy (1 if highest education is university degree or post-graduate) \\
Religious & Dummy (1 if individual's is religious) \\
City & Dummy (1 if individual's locality up to 15 had >=100.000 inhabitants) \\
FHE & Proportion of female with completed tertiary education at country level \\
Leave & Weeks maternity*replacement rates + weeks childcare*replacement rates \\
Tax & Dummy (1 if separate taxation system) \\
FvsP & Proportion of female part-time labour \\
Cohort 1951-55 & Individual is born 1951-55 (Omitted category) \\
Cohort 1956-60 & Individual is born 1956-60 \\
Cohort 1961-65 & Individual is born 1961-65 \\
Cohort 1966-70 & Individual is born 1966-70
\end{tabular}




\section{B Tables}

Table 14: Standard Taxing Reliefs in $1990^{1}$

\begin{tabular}{l|ccc}
\hline \hline Countries & Married's Relief & Children's Relief & Childminder's Relief \\
\hline \hline Belgium & $\sqrt{ }$ & $\sqrt{ }$ & $\sqrt{ }$ \\
Germany & $\sqrt{ }$ & $\sqrt{ }$ & $\sqrt{ }$ \\
Italy & $\sqrt{ }{ }^{2}$ & $\sqrt{ }$ & $\times$ \\
Spain & $\sqrt{ }$ & $\sqrt{ }$ & $\times$ \\
Sweden & $\sqrt{ }{ }^{3}$ & $\times^{4}$ & $\times$ \\
\hline \hline
\end{tabular}

${ }^{1}$ Source: OECD (1993).

${ }^{2}$ Husband's spouse credit is not given if wife's income exceeds fixed limit.

${ }^{3}$ Husband's tax credit tapers off to zero as spouse's income increases.

${ }^{4}$ Cash transfers.

Table 15: Labour Force Status of Female Aged 20-49 Years By Number of Children in $1998^{1}$

\begin{tabular}{l|l|ccccc}
\hline \hline & LFS & Belgium & Germany & Italy & Spain & Sweden $^{2}$ \\
\hline \hline \multirow{3}{*}{ O Child } & Employed & $73.0 \%$ & $81.2 \%$ & $66.9 \%$ & $65.8 \%$ & $74.1 \%$ \\
& Unemployed & $8.8 \%$ & $6.1 \%$ & $7.9 \%$ & $15.2 \%$ & $6.3 \%$ \\
& Inactive & $18.1 \%$ & $12.7 \%$ & $25.2 \%$ & $18.9 \%$ & $18.0 \%$ \\
\hline \multirow{3}{*}{ Child 0-2 } & Employed & $65.5 \%$ & $47.6 \%$ & $45.5 \%$ & $40.2 \%$ & $34.9 \%$ \\
& Unemployed & $9.6 \%$ & $3.0 \%$ & $7.7 \%$ & $12.8 \%$ & $6.5 \%$ \\
& Inactive & $24.9 \%$ & $49.2 \%$ & $46.8 \%$ & $47.0 \%$ & \\
\hline \multirow{3}{*}{ 3+ Children youngest 0-2 } & Employed & $68.0 \%$ & $43.8 \%$ & $41.1 \%$ & $36.5 \%$ & $38.5 \%$ \\
& Unemployed & $8.1 \%$ & $9.4 \%$ & $7 \%$ & $12.3 \%$ & $6.8 \%$ \\
& Inactive & $23.9 \%$ & $44.4 \%$ & $51.8 \%$ & $51.3 \%$ & \\
\hline \hline
\end{tabular}

${ }^{1}$ Source: Eurostat. Labour Force Survey. Results 1998. Theme 3. Table 11.

${ }^{2}$ Self-constructed with 1992-92 FFS survey. 
Table 16: Activity Rates of Women Aged 25-49 By Marital Status ${ }^{1,2}$

\begin{tabular}{c|l|ccccc}
\hline \hline Year & Marital Status & Belgium & Germany & Italy & Spain & Sweden $^{3}$ \\
\hline \hline \multirow{2}{*}{1991} & Single & $84.0 \%$ & $86.2 \%$ & $78.6 \%$ & $82.7 \%$ & $79.9 \%$ \\
& Married & $65.1 \%$ & $61.7 \%$ & $51.7 \%$ & $42.7 \%$ & $80.7 \%$ \\
\multirow{2}{*}{1995} & Single & $84.2 \%$ & $86.1 \%$ & $70.3 \%$ & $82.7 \%$ & \\
& Married & $69.4 \%$ & $69.7 \%$ & $52.0 \%$ & $51.0 \%$ & \\
\hline \hline
\end{tabular}

${ }^{1}$ Source 1991: Eurostat. Labour Force Survey. Results 1991. 3C. Table 04.

${ }^{2}$ Source 1995: Eurostat. Labour Force Survey. Results 1995. 3C. Table 04.

${ }^{3}$ Source for Sweden: Self-constructed with 1992-92 FFS survey. 
Table 17: Probability of Employment After $1^{\text {st }}$ Birth: following 96 Months (only those individuals whose retrospective history lasts all this period)

\begin{tabular}{|c|c|c|c|c|c|}
\hline \multirow[t]{2}{*}{ Variables } & \multicolumn{5}{|c|}{ Probit After $1^{\text {st }}$ Birth: Marginal Effects $s^{1,2}$} \\
\hline & Belgium & W-Germany & Italy & Spain & Sweden \\
\hline City $^{3}$ & $-0.058(0.042)$ & $-0.025(0.035)$ & $0.012(0.028)$ & $0.059^{* *}(0.023)$ & $0.046(0.029)$ \\
\hline Religious & $-0.082^{* *}(0.036)$ & $-0.029(0.036)$ & $-0.064(0.046)$ & $-0.138^{* *}(0.036)$ & $0.006(0.022)$ \\
\hline Married $1 C$ & $-0.182^{* *}(0.043)$ & $0.008(0.078)$ & $0.028(0.049)$ & $-0.029(0.051)$ & $-0.031(0.024)$ \\
\hline Experience $^{4}$ & $0.011^{* *}(0.002)$ & $0.020^{* *}(0.002)$ & $0.003^{* *}(0.0006)$ & $0.0006^{*}(0.0003)$ & $0.0010(0.008)$ \\
\hline AgeAt1Job & $0.113^{* *}(0.023)$ & $0.224^{* *}(0.034)$ & $0.031^{* *}(0.007)$ & $0.0007(0.001)$ & $0.021^{* *}(0.010)$ \\
\hline AgeAt1C & $-0.239^{* *}(0.072)$ & $-0.258^{* *}(0.086)$ & $0.039(0.039)$ & $-0.002(0.040)$ & $0.074(0.050)$ \\
\hline AgeAt1C2 & $0.003^{*}(0.002)$ & 0.0008 & $-0.0008(0.0008)$ & $0.002(0.0008)$ & $-0.002^{*}(0.0009)$ \\
\hline \multicolumn{6}{|l|}{ Education $^{5}$} \\
\hline$E_{2} 2$ & $-0.0017(0.034)$ & $0.177^{*}(0.092)$ & $0.059^{* *}(0.027)$ & $0.079^{* *}(0.025)$ & $-0.0001(0.071)$ \\
\hline E3Voc & $0.116^{* *}(0.038)$ & $0.249^{*}(0.149)$ & & $0.153^{* *}(0.064)$ & \\
\hline E3GrPo & $0.136^{* *}(0.054)$ & $0.422^{* *}(0.120)$ & $-0.0007(0.058)$ & $0.171^{* *}(0.085)$ & $-0.066(0.078)$ \\
\hline \multicolumn{6}{|l|}{ Cohorts $^{6}$} \\
\hline $1954^{7}$ & & & & & $-0.028(0.095)$ \\
\hline $1956-60^{8}$ & $0.041(0.037)$ & $0.061(0.067)$ & $-0.018(0.036)$ & $-0.012(0.064)$ & $-0.063(0.184)$ \\
\hline $1961-65^{9}$ & $0.110^{* *}(0.050)$ & $0.208^{*}(0.125)$ & $-0.025(0.060)$ & $-0.105(0.126)$ & $-0.114(0.262)$ \\
\hline $1966-70^{10}$ & dropped & $0.040(0.203)$ & $-0.108(0.095)$ & $-0.275(0.187)$ & dropped \\
\hline
\end{tabular}

${ }^{*}$ Significant at $10 \%$ level.

${ }^{* *}$ Significant at $5 \%$ level.

${ }^{1}$ Standard errors in brackets.

${ }^{2}$ Time dummies, year dummies and interactions not reported. They are available upon request.

${ }^{3}$ Dummy ( 1 if individual's locality up to 15 had $>=100.000$ inhabitants).

${ }^{4}$ Accumulated number of months worked up to the birth.

${ }^{5}$ Omitted category is the lowest level $(E 1)$.

${ }^{6}$ Omitted category is Cohort 1951-55 (Cohort 1952-55 for West-Germany and Cohort 1949 for Sweden).

${ }^{7}$ Cohort 1954 for Sweden only.

${ }^{8}$ Cohort 1959 for Sweden.

${ }^{9}$ Cohort 1964 for Sweden.

${ }^{10}$ Cohort 1969 for Sweden.

Note: Standard errors adjusted for clustering. 
Table 18: Probability of Employment After $1^{\text {st }}$ Birth: following 96 Months (Women who Only Had One Child Ever)

\begin{tabular}{|c|c|c|c|c|c|}
\hline \multirow[t]{2}{*}{ Variables } & \multicolumn{5}{|c|}{ Probit After $1^{\text {st }}$ Birth: Marginal Effects ${ }^{1,2}$} \\
\hline & "Belgium ${ }^{3}$ & $\overline{~ W-G e r m a n y}$ & Italy & Spain & Sweden \\
\hline City $^{4}$ & -0.125 & $-0.003(0.037)$ & $0.035(0.034)$ & $0.023(0.064)$ & $-0.094^{* *}(0.042)$ \\
\hline Religious & 0.026 & $0.012(0.035)$ & $-0.038(0.040)$ & $-0.059(0.072)$ & $0.011(0.040)$ \\
\hline Married $1 C$ & 0.015 & $-0.129^{* *}(0.050)$ & $-0.003(0.054)$ & $0.106(0.103)$ & $-0.031(0.041)$ \\
\hline Experience $^{5}$ & 0.002 & $0.010^{* *}(0.003)$ & $0.002^{*}(0.001)$ & $0.002^{*}(0.0010)$ & $0.004^{* *}(0.001)$ \\
\hline AgeAt1Job & 0.011 & $0.103^{* *}(0.029)$ & $0.025^{* *}(0.012)$ & $0.006(0.005)$ & $0.041^{* *}(0.014)$ \\
\hline AgeAt1C & 0.210 & $-0.018(0.059)$ & $-0.017(0.041)$ & $0.016(0.078)$ & $0.059(0.056)$ \\
\hline AgeAt1C2 & -0.004 & $-0.002^{* *}(0.001)$ & $-0.0001(0.0007)$ & $-0.0009(0.001)$ & $-0.0007(0.0009)$ \\
\hline \multicolumn{6}{|l|}{ Education $^{6}$} \\
\hline E2 & 0.133 & $0.186^{* *}(0.085)$ & $-0.012(0.045)$ & $0.109(0.074)$ & $-0.038(0.111)$ \\
\hline E3Voc & 0.228 & $0.300(0.219)$ & & $0.348^{* *}(0.103)$ & \\
\hline E3GrPo & $0.298^{* *}$ & $0.406^{* *}(0.206)$ & $0.025(0.084)$ & $0.310^{* *}(0.132)$ & $0.045(0.108)$ \\
\hline \multicolumn{6}{|l|}{ Cohorts $^{7}$} \\
\hline $1954^{7}$ & & & & & $0.327^{*}(0.171)$ \\
\hline $1956-60^{8}$ & -0.107 & $-0.004(0.069)$ & $0.030(0.050)$ & $-0.185(0.128)$ & $0.542^{* *}(0.249)$ \\
\hline $1961-65^{9}$ & -0.094 & $0.003(0.125)$ & $0.035(0.087)$ & $-0.204(0.198)$ & $0.748^{* *}(0.175)$ \\
\hline $1966-70^{10}$ & -0.145 & $-0.042(0.172)$ & $-0.028(0.151)$ & $-0.491^{* *}(0.211)$ & $0.720(0.125)$ \\
\hline
\end{tabular}

${ }^{*}$ Significant at $10 \%$ level.

** Significant at $5 \%$ level.

${ }^{1}$ Standard errors in brackets.

${ }^{2}$ Time dummies, year dummies and interactions not reported. They are available upon request.

${ }^{3}$ Fail in calculating second derivative, no standard deviation reported.

${ }^{4}$ Dummy (1 if individual's locality up to 15 had $>=100.000$ inhabitants).

${ }^{5}$ Accumulated number of months worked up to the birth.

${ }^{6}$ Omitted category is the lowest level (E1).

${ }^{7}$ Omitted category is Cohort 1951-55 (Cohort 1952-55 for West-Germany and Cohort 1949 for Sweden).

${ }^{8}$ Cohort 1954 for Sweden only.

${ }^{9}$ Cohort 1959 for Sweden.

${ }^{10}$ Cohort 1964 for Sweden.

${ }^{11}$ Cohort 1969 for Sweden.

Note: Standard errors adjusted for clustering. 


\section{Graphs}

Figure 7: Employment Rates Around Birth: Country and Cohort comparison
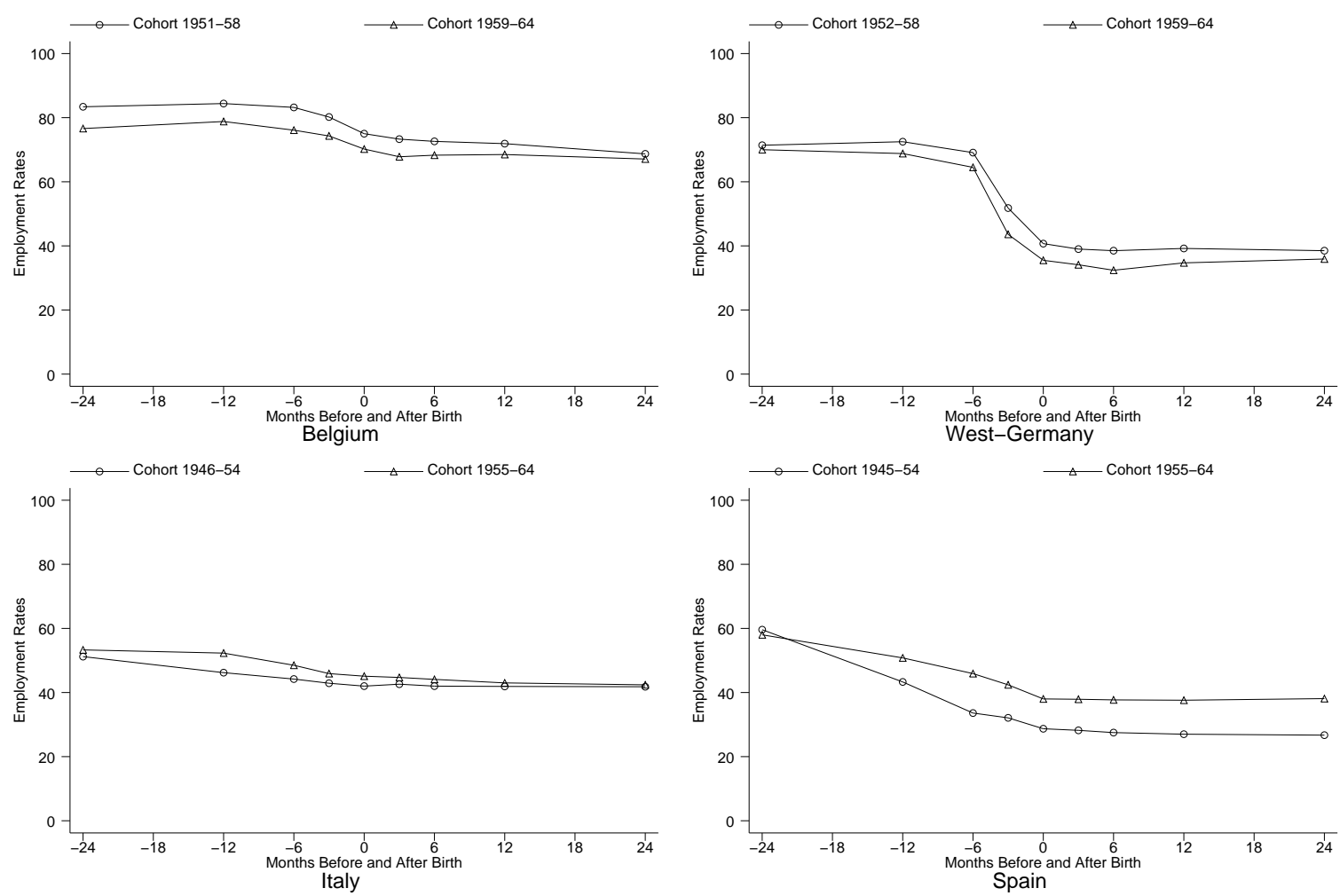
Figure 8: Employment Rates Around Marriage: Country and Cohort comparison
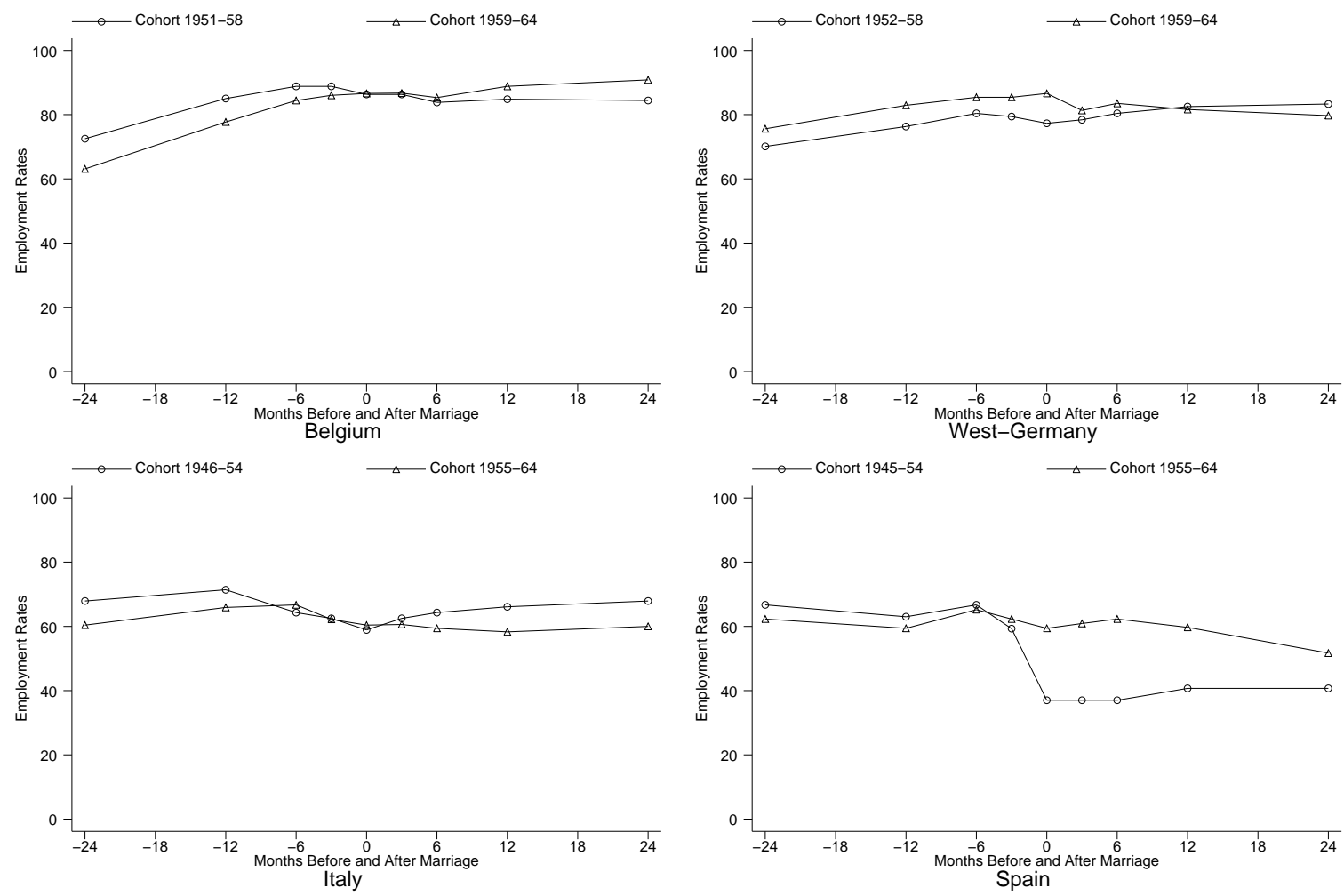


\section{CENTRE FOR ECONOMIC PERFORMANCE \\ Recent Discussion Papers}

566 T. Kirchmaier

565 P. Lopez-Garcia

564 A. Manning

563 D. Quah

562 H. Gospel

P. Willman

561 L. R. Ngai

560 M. J. Conyon

R. B. Freeman

559

R. B. Freeman

R. Schettkat

558 R. B. Freeman

557 R. B. Freeman

556 M. Guttierrez-Domenech

555
H. Gospel

J. Foreman

554 S. Machin

553 J. Blanden

S. Machin
The Performance Effects of European Demergers

Labour Market Performance and Start-Up Costs: OECD Evidence

The Real Thin Theory: Monopsony in Modern Labour Markets

Digital Goods and the New Economy

High Performance Workplaces: the Role of Employee Involvement in a Modern Economy. Evidence on the EU Directive Establishing a General Framework for Informing and Consulting Employees

Barriers and the Transition to Modern Growth

Shared Modes of Compensation and Firm

Performance: UK Evidence

Marketization of Production and the US-Europe Employment Gap

The Labour Market in the New Information Economy

Institutional Differences and Economic Performance Among OECD Countries

The Impact of the Labour Market on the Timing of Marriage and Births in Spain

The Provision of Training in Britain: Case Studies of Inter-Firm Coordination

Factors of Convergence and Divergence in Union Membership

Cross-Generation Correlations of Union Status for Young People in Britain 
552 D. Devroye

R. B. Freeman

551 M. Guadalupe

550 G. Duranton

549 S. Redding

A. J. Venables

548 T. Bayoumi

M. Haacker

547 A. B. Bernard

S. Redding

P. K. Schott

H. Simpson

546 M. Gutierrez-Domenech

545 S. Nickell

S. Redding

J. Swaffield

544 S. Machin

A. Manning

J. Swaffield

543 R. Belfield

D. Marsden

542 C. A. Pissarides

541 M. Amiti

C. A. Pissarides

540 G. Duranton

H. G. Overman
Does Inequality in Skills Explain Inequality of Earnings Across Advanced Countries?

The Hidden Costs of Fixed Term Contracts: the Impact on Work Accidents

City Size Distribution as a Consequence of the Growth Process

Explaining Cross-Country Export Performance:

International Linkages and Internal Geography

It's Not What You Make, It's How You Use IT:

Measuring the Welfare Benefits of the IT Revolution

Across Countries

Factor Price Equalization in the UK?

Employment Penalty After Motherhood in Spain

Educational Attainment, Labour Market Institutions and the Structure of Production

Where the Minimum Wage Bites Hard: the Introduction of the UK National Minimum Wage to a Low Wage Sector

Matchmaking: the Influence of Monitoring Environments on the Effectiveness of Performance Pay Systems

Consumption and Savings With Unemployment Risk: Implications for Optimal Employment Contracts

Trade and Industrial Location with Heterogeneous Labor

Testing for Localisation Using Micro-Geographic Data 